\title{
Do supra-modal traveller types exist? A travel behaviour market segmentation using Goal framing theory
}

\author{
Gustav Bösehans $^{1}$ D $\cdot$ Ian Walker ${ }^{1}$
}

Published online: 30 April 2018

(C) The Author(s) 2018

\begin{abstract}
Travel behaviour market segmentations have become a popular method of identifying different types of car users, bicyclists or public transport users. However, while previous studies have looked at different types of users within single modes, such as the car, little research has explored the existence of traveller types transcending modes. The study presented here is an extension of an earlier segmentation study that distinguished travellers based on their individual preferences, yet did so independent of their current mode choice. The data came from a travel survey at a middle-sized UK university and were analysed using a combination of hierarchical and iterative partitioning methods. Crucially, however, the current study uses a different theoretical framework to previous segmentation research-goal framing theory — which may more adequately explain the findings than models used in the past such as the theory of planned behaviour. The findings supported earlier work, suggesting the presence of seemingly stable traveller types that cut across modes and can be distinguished based on gain, hedonic and normative goals. This has important implications for policies aimed at encouraging mode change which may have been too preoccupied with changing people's attitudes rather than paying attention to people's underlying travel preferences.
\end{abstract}

Keywords Cluster analysis $\cdot$ Commuting $\cdot$ Segmentation $\cdot$ Sustainable transport $\cdot$ Travel behaviour

\section{Introduction}

Attempts to steer travel mode choice towards more sustainable alternatives are often complicated by the fact that not all people necessarily share the same preferences, making intervention difficult (Anable 2005). People may hold contrary perceptions or attitudes (e.g.

Gustav Bösehans

g.bosehans@bath.ac.uk

1 Department of Psychology, University of Bath, Office 10W 3.02, Bath BA2 7AY, UK 
public transport as too crowded and unreliable versus public transport as opportunity for pleasant encounters or to relax; Beirão and Cabral 2007) and may place a different emphasis on travel aspects such as comfort, independence or practicality (Gardner and Abraham 2007; Rubens et al. 2011). Indeed, the idea that different travellers hold different attitudes and/or preferences is common. With the aim to more effectively influence peoples' travel behaviour, policy makers and researchers alike have thus acknowledged the need to unveil the differing motivations underlying travellers' modal practices and have done so by conducting various travel behaviour market segmentations (Jensen 1999; Kaufmann 2000).

Travel behaviour market segmentations aim to classify the population into distinct groups of travellers based on the assumption that different 'mobility styles' (Barr and Prillwitz 2012) can be distinguished based on attitudinal, demographic and/or travel-related information (e.g. Diana and Mokhtarian 2009; Pronello and Camusso 2011). Often involving a combination of travellers' motives (e.g. affective instrumental and symbolic motives; Cools et al. 2009), worldviews (e.g. eco-centric versus techno-centric values; Barr and Prillwitz 2012) or attitudes (e.g. towards the environment or particular modes of travel, such as the car or cycling; Anable 2005; Jensen 1999), various such segmentations have now been conducted with general population samples to find subtypes of people who either use a particular mode (e.g. car) or a combination of modes. The bulk of segmentation research to date has considered specific travel mode users, including cyclists (Bergstrom and Magnusson 2003; Dill and McNeil 2013; Zhibin et al. 2013), car drivers and public transport users (Anable 2005; Beirão and Cabral 2008; Cools et al. 2009; Jensen 1999; Krizek and El-Geneidy 2007; Pronello and Rappazzo 2010). Similar efforts have been undertaken with more specific target groups such as day-trip travellers (Anable 2005) or tourists (Dolnicar 2002), including comparisons between daily versus short-break or holiday travel (Barr and Prillwitz 2012). While this has shed light on the differing motivations of particular types of mode users and contextual factors, it has not addressed a primary deficiency of previous segmentation work, which is how traveller segments have been conceptualized on a theoretical basis.

\section{Identifying and overcoming the limitations of previous segmentation research}

To a large extent, segmentation research to date has occurred independently, lacking both a unifying theory and a thorough integration of findings. Consequently, any further travel behaviour market segmentations may contribute only moderately to the existing body of literature. It follows that a theoretical integration of the findings from previous travel behaviour market segmentation research is long overdue.

In prominent segmentation research to date, traveller types have been defined predominantly using a mixture of attitudinal variables that arguably lacks a coherent focus. Variables range from preferences towards particular modes of travel (e.g. "I like travelling in a car"; Anable 2005), to preferences regarding specific travel characteristics (e.g. the importance attributed to travel speed, cost and comfort; Pronello and Camusso 2011), perceived symbolic aspects (e.g. "The car is a symbol of independence"; Jensen 1999), normative beliefs (Krueger et al. 2016) or views of nature (e.g. "The Earth is like a spaceship, with limited room and resources"; Barr and Prillwitz 2012), to name a few. While this in itself may not be problematic, other than reducing the comparability between segment solutions, including people's modal (behavioural) choices in the definition of segments may be (e.g. Anable 2005; Barr and Prillwitz 2012; Beirão and Cabral 2008; Cools et al. 2009; Jensen 1999; Krueger et al. 2016). 
Labels such as "Complacent Car Addicts" versus "Malcontented Motorists" (Anable 2005) and "Cyclists/Public Transport Users of Convenience" versus "Cyclists/Public Transport Users of Necessity" (Jensen 1999) are abundant in previous segmentation research, suggesting that different types of users can be distinguished within a single mode, such as the car or public transport. However, all of the aforementioned traveller type definitions included mode labels, whereas it may be more appropriate to conceptualize traveller types based on their goals or preferences independent of their current mode choice (see Pronello and Camusso 2011).

Why this may be preferable might best be illustrated in an important observation made by Anable (2005) being that "the same behaviour can take place for different reasons and that the same attitudes can lead to different behaviours" (p. 65). Thus, in the context of travel mode choice, the critical assumption being made is that not only may individuals choose a particular travel mode based on different goals or attitudes (e.g. cycling because it is fun, cheap, good for the environment, provides exercise or any combination of those), but also that despite sharing an identical set of goals or attitudes-whether it be the cost, convenience, comfort, travel time or the ecological footprint of their travel-people may actually end up using entirely different modes of transportation. This, in turn, may be primarily due to contextual factors, first and foremost the built environment, such as available infrastructure or the location of home and workplace, which may facilitate-yet not necessarily determine - some modal choices while impeding others (Næss 2015). Crucially, this calls into question the inclusion of mode in the definition of traveller types, as the latter arguably is neither particularly revealing regarding people's overarching goals nor necessarily with regard to their immediate local context.

To date, however, little to no segmentation research has established traveller profiles independent of people's mode choices, although there are exceptions, such as the work of Pronello and Camusso (2011) who strived "to define homogeneous travellers' groups based only on attitudinal variables, regardless of the behaviour in terms of mode and trip purpose" (p. 1297) or the work of Jacques et al. (2013) who extended the captive versus choice user distinction (e.g. Beimborn et al. 2003) by adding trip practicality as an additional dimension to trip satisfaction. While this research has been insightful, there is a critical element that is still missing: a sound theoretical basis for distinguishing those supra-modal and context-independent traveller types.

\section{The search for an integrative theory-based approach: Goal framing theory}

The potential for psychological theory and market segmentation to be combined has been illustrated by Anable (2005), who used theory of planned behaviour (TPB; Ajzen 1991) constructs in her work. However, the latter model's focus on behaviour being seen as the outcome of behavioural intentions that are determined by attitudes, subjective norms and perceived behavioural control-may be strongly undermined by contextual factors and habit (Pronello and Camusso 2011). Indeed, there is now ample evidence to suggest that modal choice is largely not a rational process (Innocenti et al. 2013; Lois and López-Sáez 2009; Steg 2005; Thomas 2014). Ajzen (2015) himself noted that behavioural, normative and control beliefs may be based on invalid or selective information. Extensions of the TPB have taken factors such as habit and environmental concern into account (Donald et al. 2014), although some have argued that these kinds of extensions have obscured the theory beyond recognition (Sniehotta et al. 2014). For the purpose of the current study, we 
do not intend to question the utility of the TPB as a general framework to predict intentions and behaviour, but we do question its utility for the classification of traveller types.

Specifically, we argue that traveller types should be defined not in terms of TPB constructs, but based on overarching goals. A different theoretical framework may thus be needed with, Goal framing theory (GFT; Lindenberg and Steg 2007, 2013; Steg et al. 2014a, 2016) being a promising contester.

Rather than conceptualizing people's behaviour as a result of the interplay between attitudes, norms and control beliefs, GFT (Lindenberg and Steg 2007, 2013) suggests that information processing and behaviour are guided by three overarching goals: hedonic goals which reflect the desire 'to feel better right now', gain goals which refer to the management of one's resources, as well as normative goals which include information on how to 'act appropriately'. At any given moment in time, a different goal or combination of goals may be activated or 'focal' building the 'goal frame'. The activated goal frame subsequently determines which information is attended to, how behavioural options are perceived and finally which action will be taken. As there is currently no validated instrument available to measure people's situationally dependent goal frames directly, they are approximated through measuring values. That is, it is argued that, in addition to situational factors, which goals become activated in the first place strongly depends on people's values, which are thought to affect the chronic strength of goals (Steg et al. 2016). Values serve as guiding principles in people's lives (Rokeach 1973) and "because values are fairly stable, they render some goals chronically stronger than others" (Steg et al. 2016, p. 185). Which goal frame tends to be dominant for any one given individual, across situations, may thus best be determined by measuring people's values instead. Four types of values are distinguished (Steg et al. 2014b), each relating to one of the three (situationally dependent) goals. People who endorse altruistic and biospheric values share a strong concern for the welfare of other human beings (altruistic), on the one hand, and for the quality of nature and the environment (biospheric), on the other hand. Both are considered self-transcendence values, as they focus on the collective interest, and are thus related to the normative goal. In contrast, hedonic and egoistic values focus on the gratification of personal interests, such as pleasure and enjoying life (hedonic) or social power and wealth (egoistic). Consequently, they are considered self-enhancement values and are thought to affect the chronic strength of hedonic and gain goals, respectively.

Frequently, especially with regard to pro-environmental behaviour, goals conflict, as people tend to be very sensitive to the hedonic consequences of their actions (Mann and Abraham 2006; Steg et al. 2014a, b). That is, they try to avoid situations which may involve extra effort and tend to choose the most convenient alternative of behaviour. This has an especially detrimental effect on pro-environmental behaviour which is often costly in terms of time or effort. For costly (pro-environmental) behaviours, such as transport mode choice (e.g. driving versus using public transport), utility aspects (gain goal: e.g. "I'll be faster if I drive") and anticipated affective consequences (hedonic goal: e.g. "Driving is more convenient than taking the bus"), frequently outweigh normative goals (e.g. "Taking the bus is less harmful to the environment"). However, goals can also reinforce each other. When gain and hedonic goals support the normative goal (e.g. "Taking the bus is faster and more convenient than driving"), the likelihood for sustainable behaviour to be performed may increase (De Groot and Steg 2009).

At this point, the reader may wonder why choose GFT rather than any other theoretical framework for travel behaviour market segmentation? The answer is simple: GFT's focus on the relative strength of (chronic) goals including hedonic goals (affect), gain goals (resource management) and normative goals (environment) suggests it bears high potential 
to feed into travel behaviour market segmentation analyses since ultimately, all travel is for something, if only the intrinsic satisfaction of movement. Unlike other (pro-environmental) behaviours such as recycling, which most people may do primarily because it is the right thing to do (normative goal) rather than for egoistic interests (gain goal) or because it is fun (hedonic goal), travel behaviour may involve any combination of the three overarching goals (see also Steg 2005). That is, apart from gain goals related to the management of one's resources (e.g. instrumental aspects such as cost and travel time), travel behaviour is also strongly related to hedonic goals (e.g. comfort, convenience, joy and effort) and normative goals (e.g. environmental protection). Hedonic goals, for instance, may be reflected in the journey-based affect that people anticipate from their travel mode choice (Anable 2005; Mann and Abraham 2006), whereas goals that are related to the management or improvement of one's resources may be reflected in the practicality (e.g. cost, time and effort) of people's current travel behaviour (Jacques et al. 2013). Finally, attitudes towards the environment or the benefits of sustainable travel (Anable 2005; Barr and Prillwitz 2012) may be expected to translate into normative goals (i.e. doing the right thing). The huge potential of GFT can also be observed when applied retrospectively to existing segmentation research (see Table 9 in "Appendix" for an initial summary). Consider Anable's (2005) 'Die Hard Drivers' or 'Aspiring Environmentalists'. The former appear strongly guided by hedonic goals (i.e. great pleasure in driving paired with a high attachment to the car), whereas the latter may primarily adhere to normative goals (i.e. high environmental concern and relatively low attachment to the car). This illustrative example suggests that combining segments and theory in this way, a more adaptive and theory-based travel behaviour market segmentation scheme may be developed.

\section{The present study}

We suggest the three goal frames may provide a parsimonious way to replace the various attitudinal variables that have been used in previous segmentation research. That is, GFT may add a theoretical element to travel behaviour market segmentation research which has largely been a-theoretical until the present day. Following in the footsteps of Pronello and Camusso (2011), the present study thus sought to derive goal-based preference profiles, while examining their transcendence across modes. That is, we tested whether segmenting travellers solely based on their individual preferences corresponding to the three overarching goals, irrespective of their current mode choice or travel behaviour per se, would converge with the findings of past research. Critically, however, the present study offers a theoretical integration of current and past segmentation research, using goal framing theory as a unifying theory. Needless to say, this may also have implications for the targeting and design of interventions, which will be elaborated further in the "Discussion" section.

In addition to values and a standard measure of satisfaction, the factors chosen for segmentation represented commonly recognized travel aspects including the 'three Cs' (comfort, convenience and cost in terms of money and travel time; Chatterton et al. 2009), as well as effort (Stradling 2002), environment (Anable 2005) and independence (Jensen 1999). In line with Goal framing theory (Lindenberg and Steg 2007), the choice of travel related factors attempted to include gain goals referring to the management of one's resources (i.e. cost, convenience and travel time), normative goals referring to the right course of action (environment), as well as hedonic goals referring to the desire to feel better right now (comfort and effort). A control aspect (independence) was added in line with previous research stressing the importance of autonomy (Jensen 1999; Mann and Abraham 2006; Thomas et al. 2014). The present study also included ratings of habit which has only 
rarely been measured in the context of travel behaviour market segmentation research (see Krizek and El-Geneidy 2007, for one exception). Considering that travel mode choice often involves a strong habitual component (Domarchi et al. 2008; Donald et al. 2014; Klöckner and Matthies 2004; Verplanken et al. 1997; Walker et al. 2014), including habit as an additional factor has the potential to improve taxonomies of different traveller types. In their recent work, Thomas and Walker (2015) illustrated that satisfaction and habit may vary significantly between mode users and thus may also be suitable to discriminate between traveller types.

For the study, data from a large-scale quantitative survey was used to segment a sample of current staff and student commuters of the University of Bath (a middle-sized university in the UK) via cluster analysis.

\section{Method}

\section{Participants and procedure}

Since 2008/2009, a large University Travel Survey is conducted bi-annually at the University of Bath in order to assess travel patterns of students and staff to and from the university campus, to record progress on sustainability targets and to improve travel-related facilities. An e-mail invitation to the online-based University Travel Survey was sent to all students and staff members of the university through the Vice Chancellor. Already having provided some basic demographic information (i.e. age, gender and main mode of travel for their most typical journey) in the main part of the survey, respondents could choose to continue with an optional section on which the present study is based. The 2014/15 Travel Survey, which was open to all enrolled students and staff at the university from the 4th to the 30th of November 2014, generated 2932 responses (1328 male, 1458 female, 146 missing) with 1667 respondents completing the optional part (747 male, 907 female, 13 not disclosed), including questions on psychological constructs such as habit and values (see next section).

Of those, 1249 responses were eligible for the main analysis. The mean age overall was $41.74(S D=10.98)$ for staff and $22.02(S D=5.96)$ for students and two-third of respondents $(67.3 \%)$ reported living within 15 kilometres of the University campus. An additional $14.3 \%$ of respondents (students) reported living in campus accommodation.

\section{Materials}

Respondents were asked to complete the following list of scales and items:

1. Satisfaction-Participants' general level of satisfaction with their current main mode of travel (on a Likert scale ranging from 1-very dissatisfied to 7-very satisfied).

2. Habit-Habit, here defined as the automaticity of using one's main mode of travel, was measured using a shortened version of the Habit Index (Verplanken and Orbell 2003) consisting of four items rated on a 7-point Likert scale (1-completely disagree to 7 -completely agree). The four items included "Travelling by [chosen main mode of travel] is something..." (1) I start doing before I realise it, (2) I do without thinking, (3) I do automatically and (4) I do without having to consciously remember. 
3. Mode switch — Respondents were asked to indicate if they desired to switch their current form of transport by selecting their current and desired mode from a drop-down list (e.g. current mode: car-desired mode: bicycle).

Note that, in line with our supra-modal approach, the desire to switch modes was not included in the clustering procedure (the same applies to participants' main mode of travel), but solely used for the interpretation of clusters.

4. Travel aspects-Ranking the importance of seven travel-related factors (comfort, convenience, cost, effort, environment, independence and travel time) to their usual trip.

Rather than rating the importance of each individual aspect, participants ranked the aspects by assigning rank \#1 to the most important aspect, rank \#2 to the second most important aspect, and so on. This was done so that participants had to prioritize aspects, resulting in a more distinct cluster solution. For the clustering algorithm each travel aspect was treated as a continuous variable by turning ranks into scores (Rank \#1 equal to 7 , Rank \#2 equal to $6 .$. ).

5. Values - To infer the chronic strength of people's goals, respondents completed ratings of altruistic (e.g. "A world a peace"), biospheric (e.g. "Unity with nature"), egoistic (e.g. "Social power") and hedonic (e.g. "Pleasure") values on a 16-item instrument adopted from Steg et al. (2014a, b; see also De Groot and Steg 2008), assessing these values (four items per value) on a 9-point rating scale ranging from - 1 (coded 1)-Opposed to my values to 7 (coded 9)-Of supreme importance.

Means, standard deviations and reliability measures for the clustering variables (except mode switch) are presented in Table 1. Overall, habit and value measures showed good reliability as indicated by Cronbach's alpha ranging from .72 (egoistic values) to .90 (biospheric values).

\section{Analysis}

Before grouping respondents into clusters, multinomial logistic regression analyses were carried out to assess which factors predicted mode choice for both students and staff. For

Table 1 Descriptive statistics and reliabilities of clustering variables

\begin{tabular}{lllllll}
\hline Variable & N & Min & Max & Mean & SD & Variance \\
\hline Habit average $(\alpha=.89)$ & 1249 & 1 & 7 & 3.25 & 1.60 & 2.55 \\
Satisfaction with main mode & 1249 & 1 & 7 & 4.79 & 1.65 & 2.72 \\
Average hedonic value orientation $(\alpha=.74)$ & 1249 & 1 & 9 & 6.52 & 1.37 & 1.88 \\
Average egoistic value orientation $(\alpha=.72)$ & 1249 & 1 & 9 & 4.75 & 1.25 & 1.56 \\
Average altruistic value orientation $(\alpha=.75)$ & 1249 & 1 & 9 & 7.14 & 1.21 & 1.47 \\
Average biospheric value orientation $(\alpha=.90)$ & 1249 & 1 & 9 & 6.58 & 1.50 & 2.24 \\
Travel aspect-comfort & 1249 & 1 & 7 & 3.31 & 1.62 & 2.63 \\
Travel aspect-convenience & 1249 & 1 & 7 & 5.57 & 1.42 & 2.02 \\
Travel aspect-cost & 1249 & 1 & 7 & 4.77 & 1.75 & 3.06 \\
Travel aspect-travel time & 1249 & 1 & 7 & 5.32 & 1.53 & 2.34 \\
Travel aspect-effort & 1249 & 1 & 7 & 3.16 & 1.57 & 2.48 \\
Travel aspect-environment & 1249 & 1 & 7 & 2.72 & 1.67 & 2.80 \\
Travel aspect-independence & 1249 & 1 & 7 & 3.15 & 2.08 & 4.33 \\
\hline
\end{tabular}


these analyses, main modes were collapsed into Active travel (walking and cycling), Car (alone or as/with passengers) and Public Transport (bus and train). Respondents were then grouped into segments using hierarchical cluster analysis (centroid method; Sokal and Michener 1958) based on their ratings of the seven travel aspects as well as their habit, satisfaction and value scores, to gauge the number of clusters to extract with the iterative k-means clustering procedure.

In the centroid clustering algorithm, the distance between two clusters is defined as the (squared) Euclidean distance between their centroids or means. The method maximizes the between-sets sum of squares by dividing the $\mathrm{N}$ data points into sets whose centroids (cluster averages) are at maximum distances apart (Gower 1967). The centroid method computes initial centroids for each cluster and average similarity is based on these centroids (Punj and Stewart 1983). Subsequently, data points are added successively to each set and "at any stage each set is represented by the centroid of the points currently assigned to it" (Gower 1967, p. 632). An advantage of the centroid method vis-á-vis other methods, such as Ward's method (Ward 1963), is its relative robustness against outliers, while also refraining from combining clusters with only a small number of observations (Milligan 1980), which might be regarded as a more desirable property given the larger size of the present sample. A drawback of the method is the possibility of the existence of points nearer to neighbouring centroids rather than their own. This limitation, however, is not present in the iterative portioning method (k-means).

The k-means procedure (Faber 1994; Punj and Stewart 1983), in contrast, uses a topdown approach, starting with a predetermined number of clusters to extract. At first, each case is assigned to any one of the k to-be-extracted clusters with a randomly generated cluster centroid (i.e. a reference point in an n-dimensional space based on random values of the input variables). Each individual case is subsequently tested for its "closeness" to the assigned cluster centroid. If it turns out that the case fits closer with another centroid (i.e. cluster), it will be reassigned to the corresponding cluster and all cluster centroids will be calculated anew (i.e. a new iteration process begins). The iteration process continues until all cases have been assigned to the cluster with the nearest centroid (for a more detailed discussion of the clustering procedure, please consult Blashfield and Aldenderfer 1988). Resulting clusters were then compared against demographic and travel-related information for interpretation.

\section{Results}

\section{Multinomial logistic regression (MLR) analyses}

Staff $(\mathrm{N}=545)$ and student $(\mathrm{N}=704)$ populations differed greatly in their main mode of transport, with car being the standard option for staff (63\%) and bus (58.5\%) for students (excluding students living on campus). MLR analyses were carried out to explore the factors affecting mode choice. In each case, the most frequent mode of travel was chosen as the reference group; that is, the car for staff (see Table 2) and the bus for students (see Table 3).

Overall, for staff, the odds of travelling actively increased with greater concern for the environment, but decreased with a higher importance attributed to comfort, convenience and travel time (see Table 2). Confirming the results of recent literature (Olsson et al. 2013; St-Louis et al. 2014; Thomas and Walker 2015), active commuting was also significantly 
Table 2 Parameter estimates predicting mode choice for staff using cluster variables

\begin{tabular}{|c|c|c|c|c|c|c|c|c|}
\hline \multirow[t]{3}{*}{ Variable } & \multicolumn{8}{|l|}{ Category } \\
\hline & \multicolumn{4}{|c|}{ Active travel } & \multicolumn{4}{|c|}{ Public transport } \\
\hline & $\mathrm{B}$ & SE & OR & $\mathrm{CI}$ & $\mathrm{B}$ & SE & OR & $\mathrm{CI}$ \\
\hline Intercept & $-1.98 * * *$ & .21 & & & $-1.49 * * *$ & .16 & & \\
\hline Avg hedonic & .03 & .16 & 1.03 & $.76 ; 1.41$ & .04 & .16 & 1.04 & $.76 ; 1.44$ \\
\hline Avg egoistic & -.25 & .17 & .78 & $.56 ; 1.09$ & .21 & .17 & 1.24 & $.89 ; 1.72$ \\
\hline Avg altruistic & -.10 & .18 & .91 & $.64 ; 1.29$ & -.16 & .18 & .85 & $.60 ; 1.21$ \\
\hline Avg biospheric & -.26 & .20 & .77 & $.52 ; 1.14$ & .01 & .19 & 1.01 & $.69 ; 1.47$ \\
\hline Comfort & $-.35^{*}$ & .16 & .70 & $.52 ; .96$ & -.00 & .16 & 1.00 & $.74 ; 1.37$ \\
\hline Convenience & $-.31^{\dagger}$ & .15 & .73 & $.53 ; 1.01$ & .20 & .16 & 1.22 & $.88 ; 1.68$ \\
\hline Cost & .04 & .16 & 1.04 & $.77 ; 1.40$ & $.45 * *$ & .16 & 1.57 & $1.13 ; 2.16$ \\
\hline Travel time & $-.84 * * *$ & .15 & .43 & $.32 ; .58$ & .04 & .17 & 1.04 & $.75 ; 1.45$ \\
\hline Effort & -.01 & .16 & .99 & $.72 ; 1.35$ & $.55 * * *$ & .16 & 1.73 & $1.28 ; 2.35$ \\
\hline Environment & $.72 * * *$ & .18 & 2.04 & $1.44 ; 2.91$ & $.81 * * *$ & .18 & 2.25 & $1.59 ; 3.19$ \\
\hline Independence & 0 & - & - & - & 0 & - & - & - \\
\hline Habit avg & -.15 & .15 & .86 & $.64 ; 1.15$ & -.07 & .14 & .93 & $.71 ; 1.23$ \\
\hline satisfaction avg & $.73 * * *$ & .19 & 2.07 & $1.42 ; 3.03$ & $-.83 * * *$ & .13 & .44 & $.34 ; .57$ \\
\hline
\end{tabular}

Note that, to facilitate reading of the tables, any significant predictors have been highlighted in bold

Note that the reference category for the equation is Travel by car (alone or as/with passengers). ${ }^{\dagger} p<.10$; $* p<.05 ; * * p<.01 ;$ and $* * * p<.001$

Table 3 Parameter estimates predicting mode choice for students using cluster variables

\begin{tabular}{|c|c|c|c|c|c|c|c|c|}
\hline \multirow[t]{3}{*}{ Variable } & \multicolumn{8}{|l|}{ Category } \\
\hline & \multicolumn{4}{|c|}{ Active travel } & \multicolumn{4}{|l|}{ Car } \\
\hline & $\mathrm{B}$ & SE & OR & CI & $\mathrm{B}$ & SE & OR & $\mathrm{CI}$ \\
\hline Intercept & $-.91 * * *$ & .15 & & & $-1.28 * * *$ & .16 & & \\
\hline Avg hedonic & .02 & .16 & 1.02 & $.74 ; 1.39$ & -.26 & .17 & .77 & $.55 ; 1.08$ \\
\hline Avg egoistic & -.16 & .16 & .86 & $.63 ; 1.16$ & .02 & .16 & 1.02 & $.74 ; 1.39$ \\
\hline Avg altruistic & $-.45 * *$ & .16 & .64 & $.47 ; .87$ & -.09 & .18 & .92 & $.64 ; 1.31$ \\
\hline Avg biospheric & -.03 & .18 & .97 & $.68 ; 1.38$ & $.51 *$ & .20 & 1.66 & $1.11 ; 2.47$ \\
\hline Comfort & $-.42 * *$ & .15 & .66 & $.50 ; .88$ & -.03 & .16 & .97 & $.71 ; 1.32$ \\
\hline Convenience & $-.71 * * *$ & .15 & .49 & $.37 ; .66$ & $-.38 *$ & .18 & .69 & $.49 ; .97$ \\
\hline Cost & $-.48 * *$ & .16 & .62 & $.45 ; .85$ & $-.73 * * *$ & .17 & .48 & $.34 ; .68$ \\
\hline Travel time & $-.79 * * *$ & .16 & .45 & $.33 ; .62$ & $-.79 * * *$ & .17 & .46 & $.33 ; .63$ \\
\hline Effort & $-1.04 * * *$ & .16 & .35 & $.26 ; .49$ & $-.77 * * *$ & .17 & .46 & $.33 ; .65$ \\
\hline Environment & -.16 & .18 & .85 & $.60 ; 1.22$ & $-.91 * * *$ & .22 & .40 & $.27 ; .62$ \\
\hline Independence & 0 & . & . & .. & 0 & . & . &.. \\
\hline Habit avg & $-.28^{\dagger}$ & .14 & .76 & $.57 ; 1.00$ & .11 & .15 & 1.12 & $.83 ; 1.51$ \\
\hline Satisfaction avg & $1.14 * * *$ & .18 & 3.13 & $2.21 ; 4.43$ & $.56 * *$ & .17 & 1.76 & $1.26 ; 2.45$ \\
\hline
\end{tabular}

Note that, to facilitate reading of the tables, any significant predictors have been highlighted in bold

Note that the reference category for the equation is Travel by public transport (bus/train). ${ }^{\dagger} p<.10 ; *^{*} p<.05$, $* * p<.01 ;$ and $* * * p<.001$ 
associated with higher satisfaction. Using public transport rather than the car, on the other hand, was also significantly predicted by environmental concern, in addition to a greater concern about cost and effort, albeit at the cost of lower journey satisfaction.

For students, the positive association of active travel and satisfaction was also found, although the odds of travelling actively rather than taking the bus decreased with concerns about cost, convenience, comfort, travel time and effort and, somewhat surprisingly, altruistic values (see Table 3). A similar picture emerged for car use which was, also somewhat surprisingly, predicted by biospheric values and satisfaction (albeit to a lesser extent than active commuting). As for staff, however, the environment factor increased the odds of being a public transport user rather than a car driver.

\section{Cluster analysis}

The results of the preliminary clustering process using the centroid method suggested that both, staff and student respondents, could be distinguished into three segments each. Consequently, three clusters each were extracted with the iterative k-means procedure. Tables 4 and 5 show the (unstandardized) mean scores of habit, satisfaction and values, as well as travel-related aspects for each of the six clusters. For ease of interpretation,

Table 4 Descriptive statistics for staff clusters

\begin{tabular}{|c|c|c|c|c|}
\hline \multirow[t]{2}{*}{ Factor } & \multicolumn{3}{|l|}{ Cluster } & \multirow[t]{2}{*}{ Total } \\
\hline & 1 & 2 & 3 & \\
\hline Male & 66 & 94 & 87 & 247 \\
\hline Female & 87 & 126 & 83 & 296 \\
\hline N Total & 153 & 222 & 170 & 545 \\
\hline Age & $40.55^{\mathrm{a}}(10.83)$ & $42.78^{\mathrm{a}}(11.03)$ & $40.63^{\mathrm{a}}(11.36)$ & 41.49 (11.11) \\
\hline Avg commute time & $37.05^{\mathrm{a}}(17.44)$ & $36.41^{\mathrm{a}}(20.73)$ & $44.05^{\mathrm{b}}(21.84)$ & $38.97(20.48)$ \\
\hline Avg $C_{t}$ by active & $36.18^{\mathrm{a}}(16.31)$ & $34.89^{\mathrm{a}}(13.52)$ & $34.58^{\mathrm{a}}(16.32)$ & $35.52(15.23)$ \\
\hline Avg $C_{t}$ by car & $33.12^{\mathrm{a}}(12.79)$ & $34.42^{\mathrm{a}}(19.70)$ & $40.45^{\mathrm{a}}(19.32)$ & $35.99(18.52)$ \\
\hline Avg $\mathrm{C}_{\mathrm{t}}$ by PT & $52.10^{\mathrm{b}}(25.82)$ & $61.86^{\mathrm{b}}(28.45)$ & $54.45^{\mathrm{b}}(24.57)$ & $55.08(25.41)$ \\
\hline Hedonic values & $6.58^{\mathrm{a}}(1.28)$ & $6.07^{\mathrm{b}}(1.29)$ & $5.96^{\mathrm{b}}(1.39)$ & $6.18(1.34)$ \\
\hline Egoistic values & $4.70^{\mathrm{a}}(1.18)$ & $4.29^{\mathrm{b}}(1.06)$ & $4.14^{\mathrm{b}}(1.12)$ & $4.36(1.13)$ \\
\hline Altruistic values & $7.85^{\mathrm{a}}(.84)$ & $6.73^{\mathrm{b}}(1.24)$ & $7.28^{\mathrm{c}}(1.07)$ & $7.21(1.18)$ \\
\hline Biospheric values & $7.88^{\mathrm{a}}(.91)$ & $5.99^{\mathrm{b}}(1.30)$ & $6.57^{\mathrm{c}}(1.32)$ & $6.70(1.44)$ \\
\hline Habit & $2.94^{\mathrm{a}}(1.63)$ & $2.59^{\mathrm{a}}(1.37)$ & $4.25^{\mathrm{b}}(1.48)$ & $3.21(1.64)$ \\
\hline Satisfaction & $5.67^{\mathrm{a}}(1.31)$ & $5.64^{\mathrm{a}}(1.28)$ & $3.48^{\mathrm{b}}(1.63)$ & $4.97(1.73)$ \\
\hline Comfort & $3.16^{\mathrm{a}}(1.76)$ & $3.68^{\mathrm{b}}(1.59)$ & $3.16^{\mathrm{a}}(1.49)$ & $3.38(1.63)$ \\
\hline Convenience & $5.45^{\mathrm{a}}(1.58)$ & $6.26^{\mathrm{b}}(.97)$ & $5.10^{\mathrm{a}}(1.45)$ & $5.67(1.41)$ \\
\hline Cost & $4.71^{\mathrm{a}}(1.71)$ & $3.36^{\mathrm{b}}(1.56)$ & $5.08^{\mathrm{a}}(1.50)$ & $4.27(1.77)$ \\
\hline Travel time & $4.28^{\mathrm{a}}(1.76)$ & $5.32^{b}(1.44)$ & $6.24^{\mathrm{c}}(.85)$ & $5.31(1.58)$ \\
\hline Effort & $2.33^{\mathrm{a}}(1.47)$ & $3.12^{\mathrm{b}}(1.53)$ & $3.00^{\mathrm{b}}(1.62)$ & $2.86(1.58)$ \\
\hline Environment & $4.40^{\mathrm{a}}(1.75)$ & $1.78^{\mathrm{b}}(1.00)$ & $2.84^{\mathrm{c}}(1.54)$ & $2.85(1.77)$ \\
\hline Independence & $3.67^{\mathrm{a}}(2.19)$ & $4.48^{\mathrm{b}}(1.87)$ & $2.58^{\mathrm{c}}(1.83)$ & $3.66(2.11)$ \\
\hline
\end{tabular}

Mean values with a different subscript letter $\mathrm{a}, \mathrm{b}$ or $\mathrm{c}$, differ significantly at $p<.01$ 
Table 5 Descriptive statistics for student clusters

\begin{tabular}{lllll}
\hline Factor & \multicolumn{2}{l}{ Cluster } & & Total \\
\cline { 2 - 4 } & 1 & 2 & 3 & \\
\hline Male & 142 & 105 & 78 & 325 \\
Female & 149 & 140 & 85 & 374 \\
Travelling to campus & 213 & 173 & 133 & 519 \\
Living on campus & 81 & 73 & 31 & 185 \\
N Total & 294 & 246 & 164 & 704 \\
Age & $21.12^{\mathrm{a}}(4.22)$ & $22.17^{\mathrm{a}, \mathrm{b}}(6.23)$ & $23.29^{\mathrm{b}}(7.31)$ & $21.96(5.89)$ \\
Avg commute time & $44.93^{\mathrm{a}}(20.99)$ & $42.00^{\mathrm{a}}(24.40)$ & $34.59^{\mathrm{b}}(19.94)$ & $41.31(19.27)$ \\
Avg $\mathrm{C}_{\mathrm{t}}$ by active & $34.53^{\mathrm{a}}(12.28)$ & $33.61^{\mathrm{a}}(14.50)$ & $33.01^{\mathrm{a}}(15.61)$ & $33.51(14.54)$ \\
Avg $\mathrm{C}_{\mathrm{t}}$ by car & $46.13^{\mathrm{a}}(39.42)$ & $39.06^{\mathrm{a}, \mathrm{b}}(23.59)$ & $28.19^{\mathrm{b})}(16.92)$ & $37.97(29.99)$ \\
Avg C $\mathrm{C}_{\mathrm{t}}$ by PT & $47.01^{\mathrm{a}}(16.24)$ & $44.38^{\mathrm{a}}(16.98)$ & $44.39^{\mathrm{a}}(12.54)$ & $45.67(16.21)$ \\
Hedonic values & $6.63^{\mathrm{a}}(1.36)$ & $7.10^{\mathrm{b}}(1.26)$ & $6.56^{\mathrm{a}}(1.31)$ & $6.78(1.34)$ \\
Egoistic values & $4.99^{\mathrm{a}}(1.21)$ & $5.35^{\mathrm{b}}(1.28)$ & $4.69^{\mathrm{c}}(1.19)$ & $5.04(1.26)$ \\
Altruistic values & $6.40^{\mathrm{a}}(1.23)$ & $7.82^{\mathrm{b}}(.87)$ & $7.16^{\mathrm{c}}(1.06)$ & $7.07(1.24)$ \\
Biospheric values & $5.41^{\mathrm{a}}(1.32)$ & $7.63^{\mathrm{b}}(.95)$ & $6.69^{\mathrm{c}}(1.25)$ & $6.49(1.53)$ \\
Habit & $3.28^{\mathrm{a}}(1.47)$ & $3.70^{\mathrm{b}}(1.62)$ & $2.70^{\mathrm{c}}(1.45)$ & $3.29(1.56)$ \\
Satisfaction & $4.44^{\mathrm{a}}(1.52)$ & $4.28^{\mathrm{a}}(1.60)$ & $5.60^{\mathrm{b}}(1.20)$ & $4.65(1.57)$ \\
Comfort & $3.77^{\mathrm{a}}(1.46)$ & $3.12^{\mathrm{b}}(1.62)$ & $2.52^{\mathrm{c}}(1.57)$ & $3.25(1.62)$ \\
Convenience & $5.96^{\mathrm{a}}(1.10)$ & $5.04^{\mathrm{b}}(1.47)$ & $5.35^{\mathrm{b}}(1.62)$ & $5.50(1.42)$ \\
Cost & $5.15^{\mathrm{a}}(1.58)$ & $5.55^{\mathrm{b}}(1.40)$ & $4.56^{\mathrm{c}}(1.88)$ & $5.15(1.64)$ \\
Travel time & $5.22^{\mathrm{a}}(1.46)$ & $5.90^{\mathrm{b}}(1.20)$ & $4.68^{\mathrm{c}}(1.62)$ & $5.33(1.49)$ \\
Effort & $4.19^{\mathrm{a}}(1.34)$ & $2.94^{\mathrm{b}}(1.40)$ & $2.66^{\mathrm{b}}(1.39)$ & $3.39(1.53)$ \\
Environment & $1.74^{\mathrm{a}}(.82)$ & $3.59^{\mathrm{b}}(1.61)$ & $2.76^{\mathrm{c}}(1.70)$ & $2.63(1.59)$ \\
Independence & $1.98^{\mathrm{a}}(1.29)$ & $1.85^{\mathrm{a}}(1.23)$ & $5.46^{\mathrm{b}}(1.34)$ & $2.75(1.97)$ \\
\hline & & & &
\end{tabular}

Mean values with a different subscript letter a, b or c, differ significantly at $p<.01$

a summary of the standardized mean scores is presented graphically for each cluster in Figs. 1 (Staff) and 2 (Students).

For staff, Cluster 3 differed notably from the other clusters in that members of the cluster showed a significantly higher commute time (car drivers in particular), as well as significantly higher habit and lower satisfaction ratings (see Table 4). Post-hoc comparisons revealed that the average commute time was significantly higher for Cluster 3 compared to both Cluster $1\left(M_{\text {diff }}=7,95 \%\right.$ CI $\left.1.59,12.42, p<.01\right)$ and Cluster 2 $\left(M_{\text {diff }}=7.64,95 \%\right.$ CI $\left.2.69,12.59, p<.01\right)$.

For students, a significant difference in commute time emerged between Clusters 1 and 2 and Cluster 3 (see Table 5), the latter having a significantly shorter commute time than both Cluster $1\left(M_{\text {diff }}=-10.35,95 \% \mathrm{CI}-15.35,-5.34, p<.001\right)$ and Cluster $2\left(M_{\text {diff }}=-7.42,95 \% \mathrm{CI}-12.64,-2.20, p<.01\right)$. Interestingly, members of Cluster 3 also regarded their travel behaviour as less habitual than either Cluster $1\left(M_{\text {diff }}=-.57\right.$, $95 \% \mathrm{CI}-.93,-.22, p<.001)$ or Cluster $2\left(M_{\text {diff }}=-.99,95 \% \mathrm{CI}-1.36,-.62, p<.001\right)$ and were more satisfied than either Cluster $1\left(M_{\text {diff }}=1.17,95 \% \mathrm{CI} .82,1.52, p<.001\right)$ or Cluster $2\left(M_{\text {diff }}=1.32,95 \%\right.$ CI .96, 1.68, $\left.p<.001\right)$. 
Fig. 1 Staff mean z-scores for habit and satisfaction, values and travel-related aspects (recoded) by cluster (Cluster 1 top,

Cluster 2 middle, and Cluster 3 bottom)-inner circle low
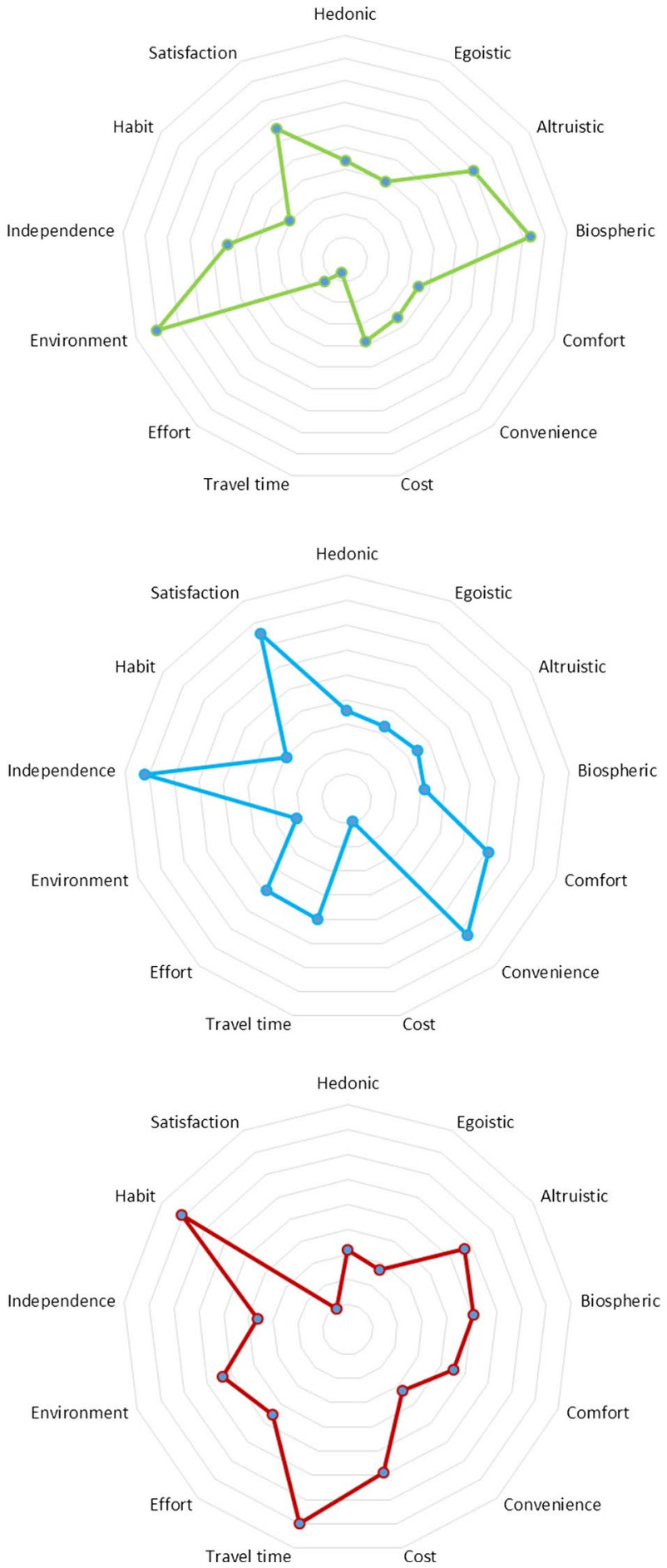
Fig. 2 Student mean z-scores for habit and satisfaction, values and travel-related aspects (recoded) by cluster (Cluster 1 top, Cluster 2 middle, and Cluster 3 bottom)-inner circle low
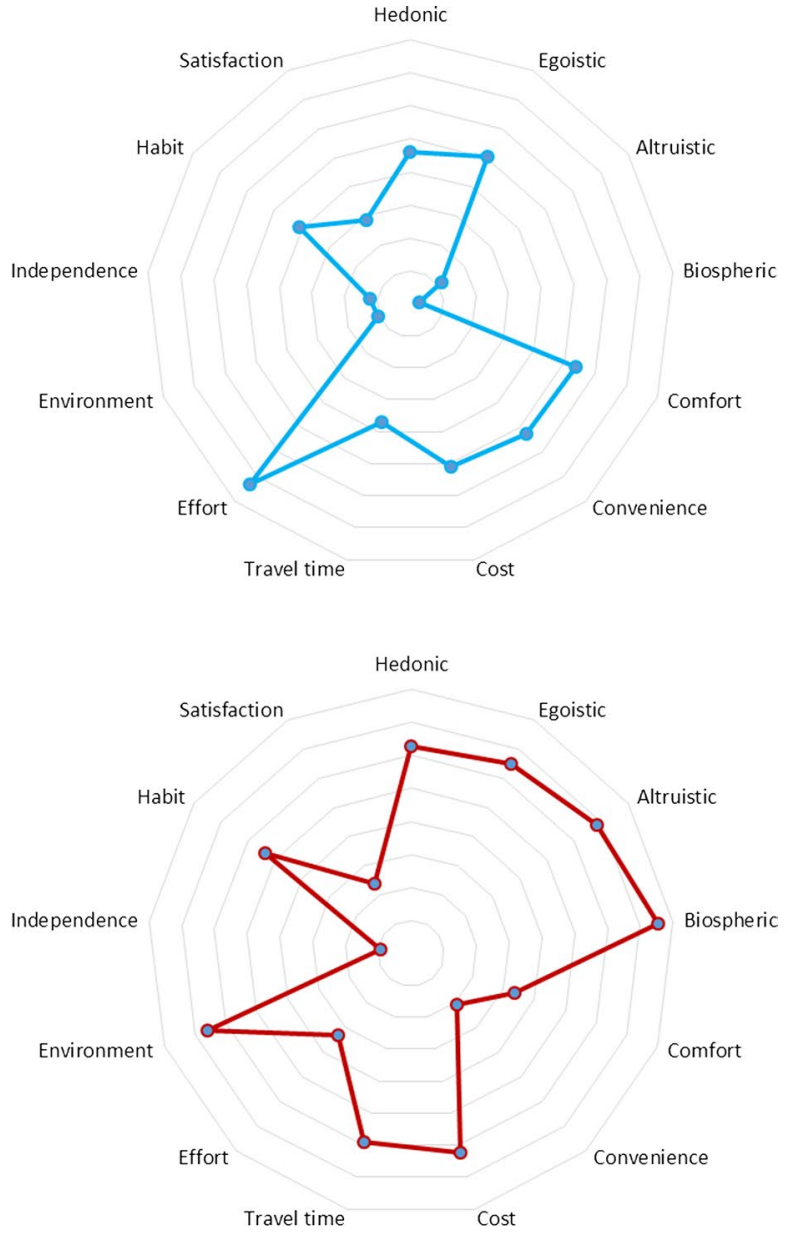

Hedonic Satisfaction Egoistic

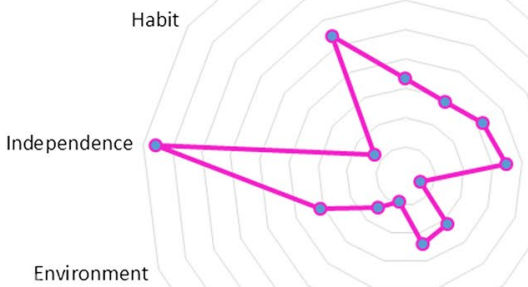

Altruistic

Biospheric

Comfort 
The following section breaks down clusters by main mode of travel and also considers which mode respondents desired, if they were contemplating a mode switch in the future. Finally, a brief description of each cluster, summarizing its key features, is provided.

Table 6 shows the main mode proportions for each of the three extracted staff and student clusters, whereas Table 7 shows the current and desired new mode, for those who expressed an inclination to switch modes in the future. For staff, the car represented the main mode of travel in all clusters $(\mathrm{C} 1: 48 \%$; $\mathrm{C} 2: 74 \%$; $\mathrm{C} 3: 62 \%)$, whereas the bus was dominant for students, yet only in the first two clusters (both 50\%). Active travel (i.e. walking and cycling) was most common in the first cluster (33.3\%) for staff and in the third cluster for students (43\%). Among those who wanted to switch travel modes in the future, active travel was the most desired among both students (31\% walk, 30\% cycle) and staff (39\% cycle, $18 \%$ walk), followed by driving alone (students: $20 \%$; staff: $18 \%$ ).

\section{Cluster interpretations}

Below, a brief interpretation of each of the three supra-modal mobility types is offered (see also Table 8 for a summary), including a fourth type that was distinguished among students and fitted the results of an earlier segmentation study by the authors (Bösehans and Walker 2016).

The first cluster represents Aspiring/Committed Environmentalists (Cluster 1, staff: $48 \%$ car, $20 \%$ bicycle, $13 \%$ walking and $12 \%$ bus) whose preferences align with the normative goal frame. Clearly, there are travellers who are strongly motivated by environmental concerns and have adjusted their travel behaviour accordingly (e.g. walking or cycling to work). This group has been variously labelled as Civic ecologists (Kaufmann 2000), Green cruisers (Beirão and Cabral 2008) or Paying ecologists (Pronello and Camusso 2011) in previous literature. In the present sample, this group is represented in Cluster 1 and stands out due to its strong altruistic and biospheric (and low egoistic/high hedonic) value orientation (Table 4). Environmentalists place little emphasis on effort or travel time and only

Table 6 Main mode by cluster and staff/student membership

\begin{tabular}{|c|c|c|c|c|c|c|c|c|}
\hline \multirow[t]{3}{*}{ Mode } & \multicolumn{8}{|c|}{ Cluster } \\
\hline & \multicolumn{4}{|c|}{ Staff commuters } & \multicolumn{4}{|c|}{ Students commuters } \\
\hline & 1 & 2 & 3 & Total & 1 & 2 & 3 & Total \\
\hline Bus & 18 & 7 & 35 & 60 & 148 & 123 & 34 & 305 \\
\hline Car (alone) & 56 & 132 & 77 & 165 & 17 & 15 & 21 & 53 \\
\hline Walk & 20 & 23 & 5 & 48 & 23 & 18 & 37 & 78 \\
\hline Bicycle & 31 & 12 & 7 & 50 & 9 & 10 & 33 & 52 \\
\hline Car (with passengers) & 13 & 26 & 19 & 58 & 8 & 2 & 5 & 15 \\
\hline Train & 3 & 7 & 16 & 26 & 2 & 2 & - & 4 \\
\hline Car (as passenger) & 4 & 6 & 9 & 19 & 5 & 1 & 1 & 7 \\
\hline Motorcycle/scooter & 6 & 1 & 1 & 8 & - & 1 & 2 & 3 \\
\hline Other & 2 & 7 & 0 & 9 & 1 & 1 & - & 2 \\
\hline Living on campus & - & - & - & - & 81 & 73 & 31 & 185 \\
\hline Total & 153 & $221^{\mathrm{a}}$ & $169^{\mathrm{a}}$ & 543 & 294 & 246 & 164 & 704 \\
\hline
\end{tabular}

${ }^{\mathrm{a}} \mathrm{N}=1$ missing in each 
Table 7 Current and desired mode by cluster membership for students and staff

\begin{tabular}{|c|c|c|c|c|c|c|c|c|}
\hline \multirow[t]{3}{*}{ Mode } & \multicolumn{8}{|c|}{ Cluster } \\
\hline & \multicolumn{4}{|c|}{ Current mode } & \multicolumn{4}{|c|}{ Desired mode } \\
\hline & 1 & 2 & 3 & Total & 1 & 2 & 3 & Total \\
\hline \multicolumn{9}{|l|}{ Student } \\
\hline Bus & 62 & 55 & 17 & 134 & 8 & 4 & 3 & 15 \\
\hline Car (alone) & 1 & 7 & 5 & 13 & 16 & 14 & 4 & 34 \\
\hline Walk & 8 & 2 & 5 & 15 & 19 & 25 & 8 & 52 \\
\hline Bicycle & 3 & 3 & 3 & 9 & 21 & 20 & 9 & 50 \\
\hline Train & 1 & 2 & - & 3 & - & - & - & - \\
\hline Car (as passenger) & 2 & - & - & 2 & 4 & - & 1 & 5 \\
\hline Motorcycle/scooter & - & - & - & - & 3 & 4 & 2 & 9 \\
\hline Other & - & - & - & - & 1 & 1 & - & 2 \\
\hline Total & 77 & 69 & 30 & 176 & 72 & 68 & 27 & 167 \\
\hline \multicolumn{9}{|l|}{ Staff } \\
\hline Bus & 6 & 1 & 19 & 26 & 3 & 1 & 5 & 9 \\
\hline Car (alone) & 14 & 25 & 22 & 61 & 4 & 4 & 11 & 19 \\
\hline Walk & 2 & 4 & - & 6 & 4 & 7 & 8 & 19 \\
\hline Bicycle & 3 & 3 & 1 & 7 & 12 & 16 & 13 & 41 \\
\hline Train & - & 3 & 1 & 4 & 1 & 1 & 3 & 5 \\
\hline Car (as passenger) & 1 & - & 1 & 2 & - & 2 & 3 & 5 \\
\hline Motorcycle/scooter & - & - & 1 & 1 & - & 2 & 1 & 3 \\
\hline Other & - & - & - & - & - & 2 & 1 & 3 \\
\hline Total & 26 & 36 & 45 & 107 & 24 & 35 & 45 & 104 \\
\hline
\end{tabular}

'Car with passengers' was not selected by any student or staff members

attribute a moderate importance to other instrumental factors, such as cost and comfort, or independence. In terms of mode choice, the cluster is almost equally divided by car (48\%) and alternative (public) transport users (20\% bicycle, $13 \%$ walking and $12 \%$ bus) which, at first sight, seems surprising given their strong ecological commitment. The high proportion of car users suggests that a distinction can be made between Aspiring and Committed Environmentalists (see also Anable 2005; Prillwitz and Barr 2011). The former have a desire to commit to more sustainable travel options (e.g. active travel or driving an electric vehicle), whereas the latter have already made such an advance. Further data suggested that Environmentalists generally regarded their travel behaviour as moderately habitual and tended to be satisfied with their current form of travel, supporting the notion that active travel in particular may hold affective benefits (Gatersleben and Uzzell 2007).

The second cluster consists of Convenience Lovers (Cluster 2, staff: $74 \%$ car; $15 \%$ active travel; Cluster 1, student: $50 \%$ bus; $10 \%$ Car; $8 \%$ Walking) who prioritise hedonic goals. Comparable to Anable's (2005) Complacent Car Addicts or Jensen's (1999) Passionate car drivers - these travellers are relatively satisfied with their current form of travel, do not perceive their travel behaviour as very habitual and neither care about the cost nor the environmental impact of their travel mode choice (Table 4). They desire convenience (highest) and independence (highest) at any cost. Due to their strong desire for autonomy and freedom (Anable 2005; Jensen 1999; Thomas et al. 2014), these dedicated mode users may not 


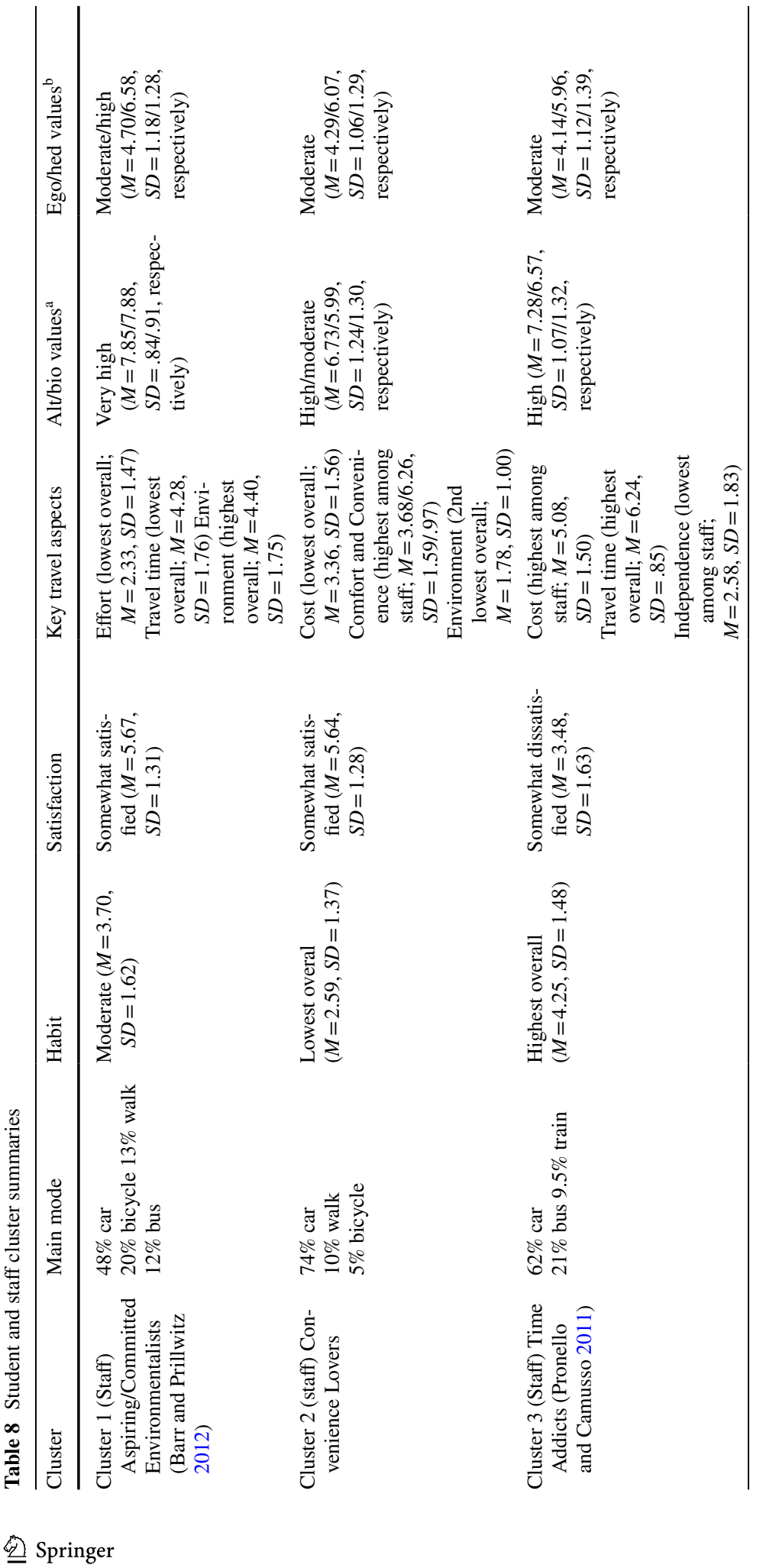



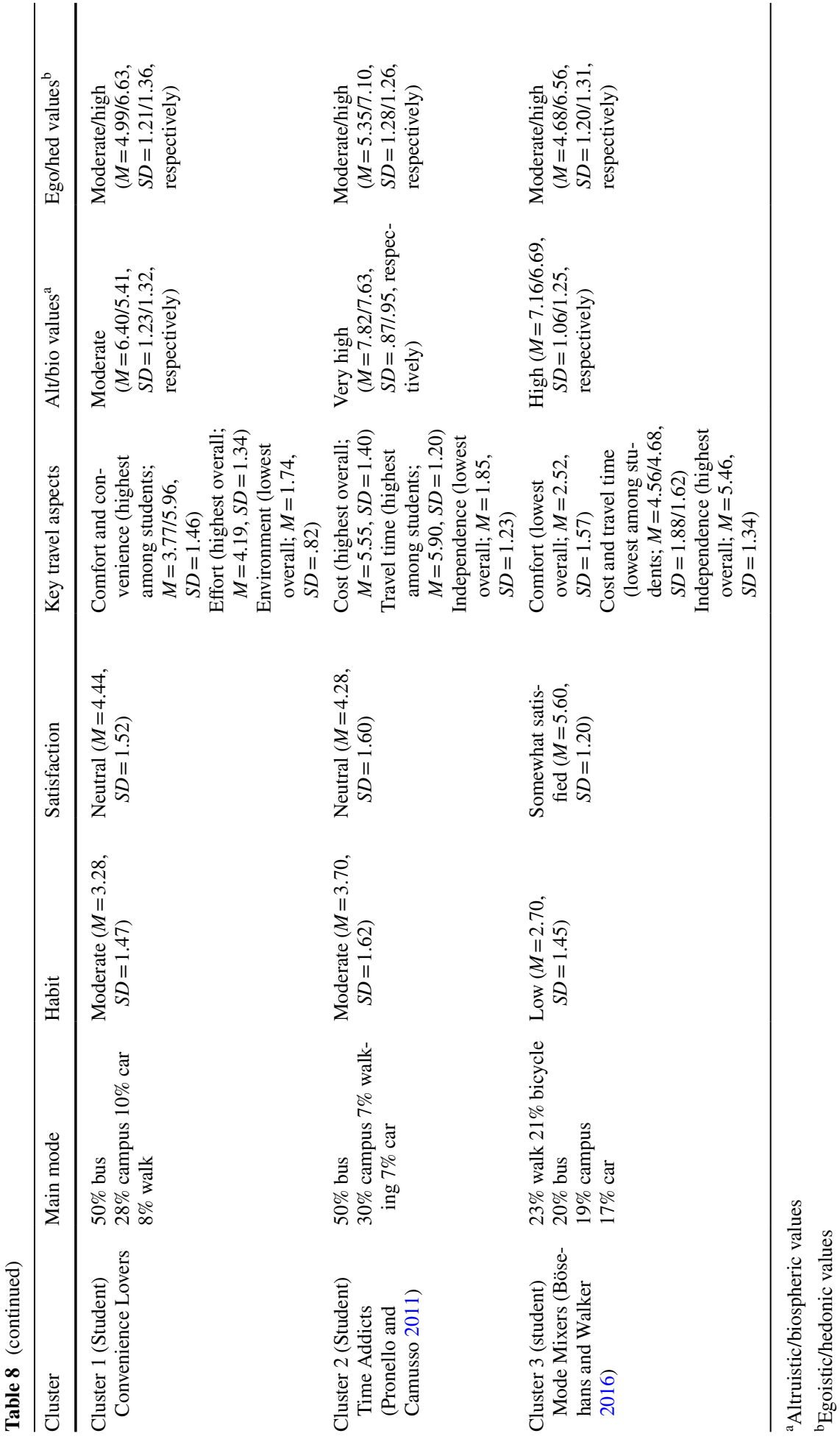
be easily persuaded to travel more actively and sustainably, unless the alternative provides a similar degree of convenience and independence. It is likely that, even if members of this cluster were to acknowledge the environmental impact of their travel habits, attempts to encourage more sustainable travel that is less convenient, or limits their perceived freedom, would be met with strong resistance or provoke reactance, re-enforcing the already strong attachment to their mode (e.g. Tertoolen et al. 1998). In line with Paulssen et al. (2014), the desire for flexibility (here: independence) decreases the willingness to use public transport, which very likely explains the low proportion of public transport users in this particular cluster. However, there was a small proportion of active travellers in this cluster, implying that, even in the absence of environmental concern, walking and cycling may be perceived to provide both convenience and independence. Some notable differences were apparent between staff and student Convenience Lovers.

In some regards, student Convenience Lovers resembled staff Convenience Lovers in their strong desire for comfortable and convenient travel paired with low environmental concern (Table 5). Overall, student Convenience Lovers were neither particularly satisfied nor dissatisfied with their main mode of travel, felt their travel routine was moderately habitual, and were not willing to make sacrifices with regard to any of the "three Cs" (Chatterton et al. 2009)— that is, the Convenience, Cost and Comfort-of their mode. This was underlined by their high emphasis placed on effort (highest overall), suggesting that these students desire to maximise both the experienced journey satisfaction and practicality of their trip (see the Convenience cluster by Jacques et al. 2013). A major difference to the staff cluster, however, emerged in the importance attributed to cost and independence. These differences in characteristics may be explained by students having less financial resources available, and thus having to pay more attention to travel costs, while also having a lower need to be independent, or to demonstrate independence (e.g. through ownership of a car), at this stage of their lives.

Members of the third goal-based cluster attributed particular importance to gain goals (first and foremost travel time) and were consequently labelled Time Addicts (Cluster 3, staff: $62 \%$ car, $30.5 \%$ bus or train; Cluster 2 , student: $50 \%$ bus, $7 \%$ walking, $7 \%$ car). Time Addicts are fairly neutral (somewhat dissatisfied in the case of staff) towards their current form of travel, which they regard as fairly automatically driven (highest mean among both students and staff). They tend to be very cost-conscious and favour alternatives based on the level of trip practicality provided - that is, convenience and, above all, travel time performance (see Tables 4, 5). Moreover, independence does not play a huge role in their decision and the environmental impact of their travel is unlikely to be a decisive factor for staff Time Addicts, although environment was a concern for student Time Addicts. In general, Time Addicts may be likely to balance the costs and benefits of various travel options and then choose the option with the best value-for-money performance on relevant criteria, particularly cost and travel time (i.e. they could also be seen as Utilitarianists as defined by Jacques et al. 2013). For staff, Time Addicts showed a significantly higher travel time than the remaining clusters (about $7 \mathrm{~min}$ more on average) and the largest proportion of public transport users $(30.5 \%)$. The latter spent on average 14-20 min more on their commute than either active travellers or car drivers, suggesting that increased time spent on public transport may account for the observed difference in satisfaction, as desired expectations regarding travel time were potentially not met. This is further supported by the relatively high number of individuals intending to switch to the car (24\% of those considering a mode switch compared to $17 \%$ in Cluster 1 and $11 \%$ in Cluster 2).

Finally, a fourth cluster labelled as Mode Mixers (Cluster 3, student: $22.5 \%$ walk; $21 \%$ bicycle; $20 \%$ bus; $17 \%$ car) could be distinguished. Mode Mixers, as identified in previous 
research by the authors (Bösehans and Walker 2016), are 'open to all possibilities' (see also Kaufmann 2000). They have a very strong desire for independence (highest mean overall), regardless of the travel alternative chosen, suggesting that any mode, or any combination of modes, has the potential to fulfil the desire for independence and a given person's mode choice is likely influenced by the desire for this. Instrumental aspects such cost and travel time do matter to Mode Mixers, yet generally less so than to the remaining student clusters. Comfort and effort are no concern for them, and neither is environmental concern, thus setting them apart from the Aspiring/Committed Environmentalists. Members of this cluster were the most satisfied among student travellers and equally satisfied as the Aspiring/Committed Environmentalists and Convenience Lovers. Like the latter two clusters, they also perceived their travel to be less automatic and habitual. Due to little overlap with existing literature, it is not clear, however, whether Mode Mixers represent a truly unique cluster or one that is specific to the local context examined.

\section{Discussion}

A primary purpose of travel behaviour market segmentations is to recognise the diversity in needs and perceptions of various road users (Jensen 1999). The present study has illustrated that three supra-modal (i.e. mode-independent) traveller types could be distinguished across students and staff who place a different emphasis on three overarching goal frames (i.e. gain, hedonic and normative). The extracted segments broadly mirrored the results of earlier segmentation research, but intentionally excluded mode choice from cluster definitions (Pronello and Camusso 2011) and added a theoretical framework, Goal framing theory (Lindenberg and Steg 2007), as the basis for defining mobility types. The significant overlap between the present travel behaviour market segmentation based on GFT and past research (Anable 2005; Barr and Prillwitz 2012; Beirão and Cabral 2008; Jacques et al. 2013; Jensen 1999; Kaufmann 2000; Prillwitz and Barr 2011; Pronello and Camusso 2011) suggests that modal choice should not be regarded as the outcome of a behavioural predisposition towards that mode (Krueger et al. 2016), but due to an interaction between the individual's goals - whether those be gain-related (e.g. managing one's resources such as time and money), hedonic (i.e. having an easy and pleasant journey) or normative (e.g. reducing the environmental impact of one's travel behaviour by choosing sustainable transport options) - and the context in which the travel behaviour occurs (Næss 2015). This is also supported by Cools et al. (2009) who found that, except for car-dependent travellers who evidenced 'car stickiness' (Innocenti et al. 2013), none of their remaining segments showed an initial preference for a particular travel mode.

In addition to mode-independence, the proposed goal-based traveller type distinction also supports findings on the relative strength of gain and hedonic goal frames as opposed to a normative goal frame (Steg et al. 2014a, b). Two of the major clusters distinguished in the present study and identified in one form or another in various previous segmentation work (Anable 2005; Barr and Prillwitz 2012; Jacques et al. 2013; Pronello and Camusso 2011) - that is, Convenience Lovers and Time Addicts - appear to be strongly influenced by hedonic or instrumental (gain-related) motives and thus may be rather unlikely to be swayed by soft policy measures, especially those targeted at a normative goal frame. Instead, the latter segments might be better influenced by goal-congruent improvements in service provision and infrastructure or sufficiently strong (dis-)incentives, thus 'decreasing the (hedonic and gain) costs of pro-environmental choices' (Steg et al. 2014a, b, p. 104). Of course, this is not to say that travellers may not base their modal choices on invalid or 
selective beliefs that lead to biased choices (Ajzen 2015; Innocenti et al. 2013; López-Sáez et al. 2016). However, in line with Næss (2015), travel behaviour might arguably be better regarded as probabilistic rather than possibilistic. In other words, in spite of the variability in people's individual goals or instrumental, symbolic and affective beliefs (e.g. Lois and López-Sáez 2009), the built environment is thought to place (absolute) constraints on an individual's travel behaviour to the extent that it makes certain transport options more attractive and feasible than others and thus may ultimately determine travel mode choice.

Due to this interdependence between goals and context, policies and interventions may thus need to reshape social, economic and urban environments to successfully tackle the various needs of different population segments in order to engender any lasting changes (Barr and Prillwitz 2014). This also requires that common transport taboos are addressed with sufficient rigour (Gössling and Cohen 2014). Thus, interdisciplinary research should continue to investigate the factors affecting the public acceptance of legal measures (e.g. Gärling and Schuitema 2007; Tørnblad et al. 2014), understanding the adoption of new technologies (e.g. Bockarjova and Steg 2014; Schuitema et al. 2013) and sustainable travel behaviours (Steg et al. 2014a), while evaluating changes in behaviour and attitudes in response to changes in the built environment (Ogilvie et al. 2012) or social practices. At the same time, it will be critical to further study the effectiveness of urban design and land use measures to encourage active travel and public transport usage, which has remained a largely understudied area (Ewing and Cervero 2010; Goodman et al. 2014; Heath et al. 2006; Khan et al. 2014).

\section{Strengths and limitations}

The general problem with cluster analysis producing clusters regardless of whether or not extracted groupings may actually exist in the real world persists. Cluster analysis remains an exploratory tool and each cluster solution is merely one of many possible outcomes based on the researcher's choice of data included, clustering algorithm and distance measure applied, and number of clusters selected (Dolnicar 2002). In addition, the input variables are always chosen subjectively, thus precluding the inclusion of other variables which may have led to vastly different results. Furthermore, it is unlikely that any individual will perfectly fit into any one of the extracted groupings due to the complex interaction of fluctuating internal and external factors, thus limiting the generalizability of any cluster solution. A traveller might, for instance, value both the environment and travel time highly, under which circumstances it might become difficult to classify him or her as either an Aspiring (Committed) Environmentalist or Time Addict, respectively.

Moreover, while the primary objective of the present study was to derive a supra-modal traveller type distinction, one could argue that the staff-student dichotomy actually reintroduced in some way the modal segmentation (i.e. between the car used mainly by staff and public transport mainly used by students) that the authors looked to avoid. While this argument cannot be entirely refuted, the following should be considered. In line with our argument, people can share the same motives, yet use entirely different means of transportation. For example, Convenience Lovers emerged as a cluster for both students and staff, although half of the former use the bus and three quarter of the latter use the car. Similarly, people who endorse even opposing values (Aspiring Environmentalists) may still use the same mode ( $48 \%$ car), often due to contextual factors, as elaborated below. Thus, while it is hardly surprising that staff and students rely on different main modes of travel, to a large 
extent due to their differing life situation, the authors would like to encourage both policyand decision makers alike to refrain from forcing mode labels on any traveller type.

Another limitation relates to the lack of inclusion of contextual variables. Travel behaviour is characterised by a "context-dependent multi-causality" (Næss 2015, p. 280). That is, it rarely has a single cause, but usually originates from the interplay of a multitude of potential casual influences. Those causal influences normally relate to the powers of agency (i.e. individuals' knowledge, attitudes, goals and resources) and structure (i.e. the built environment encompassing features such as street connectedness, city compactness and mixed land use). As a consequence, modal choice might be better regarded as an endproduct of the interaction between goals and the ability of the context to fulfil these goals. In other words, the local (spatial) context mediates the goal-behaviour relationship. This is especially evident in the event of an office- or household relocation (Walker et al. 2014; Verplanken and Roy 2016), where new contextual factors may play a significant role in negotiating existing personal goals and attitudes with available behavioural options (Steg and Vlek 2009). Other contextual factors might include the quality of public transport services (e.g. Jain et al. 2014), the availability of facilities (Larsen and El-Geneidy 2011) or legal restrictions (e.g. taxes, congestion charges; Hensher 2008), although individual perceptions and attitudes may play a role (Redman et al. 2013). Due to the survey being a routine travel survey, however, factors such as the urban environment (Banerjee and Hine 2014), were not considered in the present study, thus leaving the interaction between different traveller types' (chronic) goals and the environment open to further investigation. These limitations notwithstanding, the present typology of commuters can be distinguished from earlier segmentation research in several ways.

First, the current classification is supra-modal by focusing solely on commuters' preferences and values while, at the same time, providing more detailed information about individual segments than comparable supra-modal approaches (Jacques et al. 2013). Second, the classification did not include attitudes towards particular transport alternatives such as the car (Anable 2005), thus avoiding any potential response bias due to identity threats (Murtagh et al. 2012). Third, similar to the work of Jacques et al. (2013), the study did not employ a general population sample (Cools et al. 2009; Diana and Mokhtarian 2009; Pronello and Camusso 2011), but rather a sample of demographically similar commuters with a homogeneous trip purpose and destination (i.e. the commute to university campus). Thus, no extra steps were necessary to control for potentially confounding variables such as trip purpose and destination (Barr and Prillwitz 2012). Finally, with one exception, the same clusters were found among both students and staff, suggesting a high degree of stability of the extracted segments, which were in line with past research.

Indeed, despite conceptual differences and methodological limitations, the present study has shown that a strong consensus prevails among previous segmentation solutions obtained by different researchers in different parts of the world and at different time points (Anable 2005; Barr and Prillwitz 2012; Beirão and Cabral 2008; Cools et al. 2009; Jacques et al. 2013; Jensen 1999; Kaufmann 2000; Prillwitz and Barr 2011; Pronello and Camusso 2011). Most importantly, by omitting modal choice from the definition of clusters and by adding a theoretical basis to the vast array of past segmentation research, supra-modal traveller types could be identified (Pronello and Camusso 2011) that provide an alternative to common TPB-based approaches (e.g. Anable 2005). More specifically, in contrast to recent research which has argued that people may possess behavioural predispositions towards particular transport modes (Krueger et al. 2016), we argue the exact opposite. That is, rather than being predisposed towards certain modes of travel-as some individuals with a particularly strong attachment and positive attitude to their mode (such as Anable's Die 
hard Drivers) might be-most individuals might be better thought of as being predisposed towards specific goals they wish to fulfil. In particular, the results suggests the presence of three mobility types that appear to closely mirror the three goal frames distinguished by Lindenberg and Steg (2007), reflecting people's hedonic goals (Convenience Lovers), gain goals (Time addicts) and normative goals (Aspiring/Committed Environmentalists). Using these goal-based clusters, some tentative recommendations as to how their travel behaviour might be influenced towards more sustainable alternatives can be made.

\section{Implications}

The present study has illustrated that elaborate psychological models of modal choice (e.g. Donald et al. 2014; Paulssen et al. 2014) may actually overcomplicate the modal choice process, which may be much more reliant on goal-based preference profiles and contextual factors than some would like to make us believe. Social Psychology infused transportation research has proven incredibly valuable in revealing and testing a host of potential motives behind people's travel mode choices (e.g. Donald et al. 2014; Gatersleben and Uzzell 2007; LaJeunesse and Rodríguez 2012; Mann and Abraham 2006; Paulssen et al. 2014; Steg 2005; Steg et al. 2001; just to name a few) and soft policy measures have shown a notable potential in reducing car use (García-Garcés et al. 2016; Möser and Bamberg 2008). The current study as well supports the notion that specific psychological factors such as independence (Jensen 1999; Thomas et al. 2014) and environmental concern (Anable 2005) may play a significant role in travel mode choice for some people, although the strength of hedonic and gain goals should not be underestimated. This has important implications for the way transport policies and interventions are designed, especially interventions based on social marketing approaches (Peattie and Peattie 2009). Here, we provide some tentative recommendations based on the extracted supra-modal traveller types.

\section{Aspiring/committed environmentalists}

Recommendations Due to their relatively small emphasis placed on travel mode performance in terms of time and effort required, and high importance attributed to the environment, these users may have the greatest propensity to alter their travel behaviour. Financial incentives (e.g. subsidies for purchasing an electric bicycle or plug-in battery/hybrid EV; free charging/parking space at the workplace), infrastructure improvements (e.g. exclusive bus lanes, new segregated cycle paths) or Personalised Travel Planning Interventions (PTPIs; e.g. Graham-Rowe et al. 2011) may enable the Aspiring Environmentalist to fully commit to more sustainable travel alternatives in the long run. Increasing trip comfort, the aesthetic quality of the trip route or trip safety would benefit the Committed Environmentalists (i.e. those already traveling by sustainable means), whereas appealing to individuals' environmental beliefs or local identity and improving the accessibility and cost of public transport (Collins and Chambers 2005; Jaśkiewicz and Besta 2014), may be particularly effective to target the drivers in this cluster.

\section{Convenience lovers}

Recommendations Increasing the actual or perceived convenience of alternatives may be crucial for Convenience Lovers. Although not as time-sensitive as the Time Addicts below, for these users, mode change will require the availability of highly competitive alternatives 
(e.g. a well-connected network of segregated cycle paths or frequent and reliable public transport with stops at convenient locations) that provide a high degree of comfort, flexibility and independence. Convenience Lovers may be willing to pay whatever the price for the most convenient alternative but, at the same time, may settle for nothing less. Finally, for this cluster, appealing to normative considerations is unlikely to encourage a shift in behaviour.

\section{Time addicts}

Recommendations Clearly, mode performance is vital in the eyes of Time addicts and thus any regulatory or physical changes that lower the cost and enhance the performance of sustainable travel modes (e.g. cycle superhighways or exclusive bus lanes) are likely to facilitate mode change for this group (e.g. Schneider 2013). Information about trip time variability may be useful to convince Time Addicts to switch from the car to common alternative modes such as public transportation (López-Sáez et al. 2016). Yet, in this case, the self-reported data clearly indicate that the car outperforms public transport in terms of travel time, thus making a switch unlikely, although active travel might still be an option.

\section{Mode mixers}

Recommendations Sixty-three percent of Mode Mixers who intended a switch in travel modes cited either walking or cycling as a desired alternative, suggesting that they might benefit from the same interventions directed at Aspiring or Committed Environmentalists. To preserve their strong desire for independence (see also Thomas et al. 2014, for the importance that different mode users attribute to autonomy), flexible public transport tickets that can be used with multiple services (e.g. bus, train and metro) could provide an additional benefit, or the flexibility and control of walking and cycling (Gatersleben and Uzzell 2007) might be promoted.

\section{Future research}

Due to the consistent overlap between the current and previous segmentation work, it seems reasonable to assume that the traveller types distinguished here can broadly reflect the vast majority of commuters. Table 9 in "Appendix" provides an initial attempt to capture this consensus in a more accessible way, using Goal framing theory (Lindenberg and Steg 2007) for the classification of clusters. In addition, Jensen's (1999) two factors that did not feature in the other segmentation studies (i.e. freedom/independence and habit), but were part of the present study, are included, as is the TPB factor perceived behavioural control (PBC) used by Anable (2005) which may also be expected to be an important aspect in distinguishing transport users. In this illustrative review of some of the most prominent segmentation research to date, the clusters extracted in the present study re-emerge- that is, Aspiring/Committed Environmentalists, Convenience Lovers and Time Addicts.

The tentative integration of present and past work (Table 9) suggests that there may be additional clusters (Perceived/True Captivity, Dedication and Mode Mixers) that represent preference profiles in their own right. To what extent each of the latter reflects true preference profiles, however, remains open to debate.

There are, however, additional issues in segmentation research that remain unresolved and deserve attention. To date, little is also known about the formation of preference 
profiles. It is likely that parenting practices may have a strong impact on the preferences that their children develop (Pooley et al. 2013). Taking children to school in a car as opposed to active travel or public transport, could lead children to prioritize different goals and values, such as convenience and comfort, in the future. It is also conceivable, however, that goal-based preference profiles do not materialize until adulthood, when independent travel decisions, such as the commute to work, need to be made. Little is also known about the stability and permeability of traveller types over time and across different contexts (e.g. commute versus leisure). Major life events, such as a relocation or a change in family or occupation status, could also prove influential (SEGMENT 2016; Verplanken and Roy 2016). Longitudinal research studies may shed more light on this issue. Finally, it needs to be explored in more detail how chronic goal tendencies influence decision-making in specific contexts and situations. This also includes the necessity to develop instruments to measure active goal frames directly rather than chronic goal tendencies (i.e. values).

\section{Conclusion}

Earlier segmentation studies have shown that users of a single mode may have different individual preference profiles. The present study extends this by demonstrating that those who share a preference profile may use entirely different modes of transport. Individual traveller types may thus be better regarded independent of their travel mode choice. This has important implications for the promotion of active and sustainable travel which may have inordinately focused on attitudes towards different transport modes rather than on people's underlying supra-modal goal tendencies. Indeed, the first application of Goal framing theory to travel behaviour market segmentation research has suggested that motivations may be effectively reduced to gain, hedonic and normative goals, although this is not to undermine the value of context-specific segmentation studies that can be more nuanced and reveal important information about local people's behaviours. Undoubtedly, travel behaviour is a complex and multi-faceted process implying that any legal, structural or behavioural measures will need to address all traveller types' needs simultaneously. This implies that sustainable alternatives need to become not only more affordable, convenient and time-saving, but also need to provide a sufficient degree of autonomy. While this may be difficult to achieve in reality, it appears to be the only reliable way to effectively encourage behaviour change in the long run.

\section{Compliance with ethical standards}

Conflict of interest The authors declare that they have no conflict of interest.

Open Access This article is distributed under the terms of the Creative Commons Attribution 4.0 International License (http://creativecommons.org/licenses/by/4.0/), which permits unrestricted use, distribution, and reproduction in any medium, provided you give appropriate credit to the original author(s) and the source, provide a link to the Creative Commons license, and indicate if changes were made.

\section{Appendix}

See Table 9. 


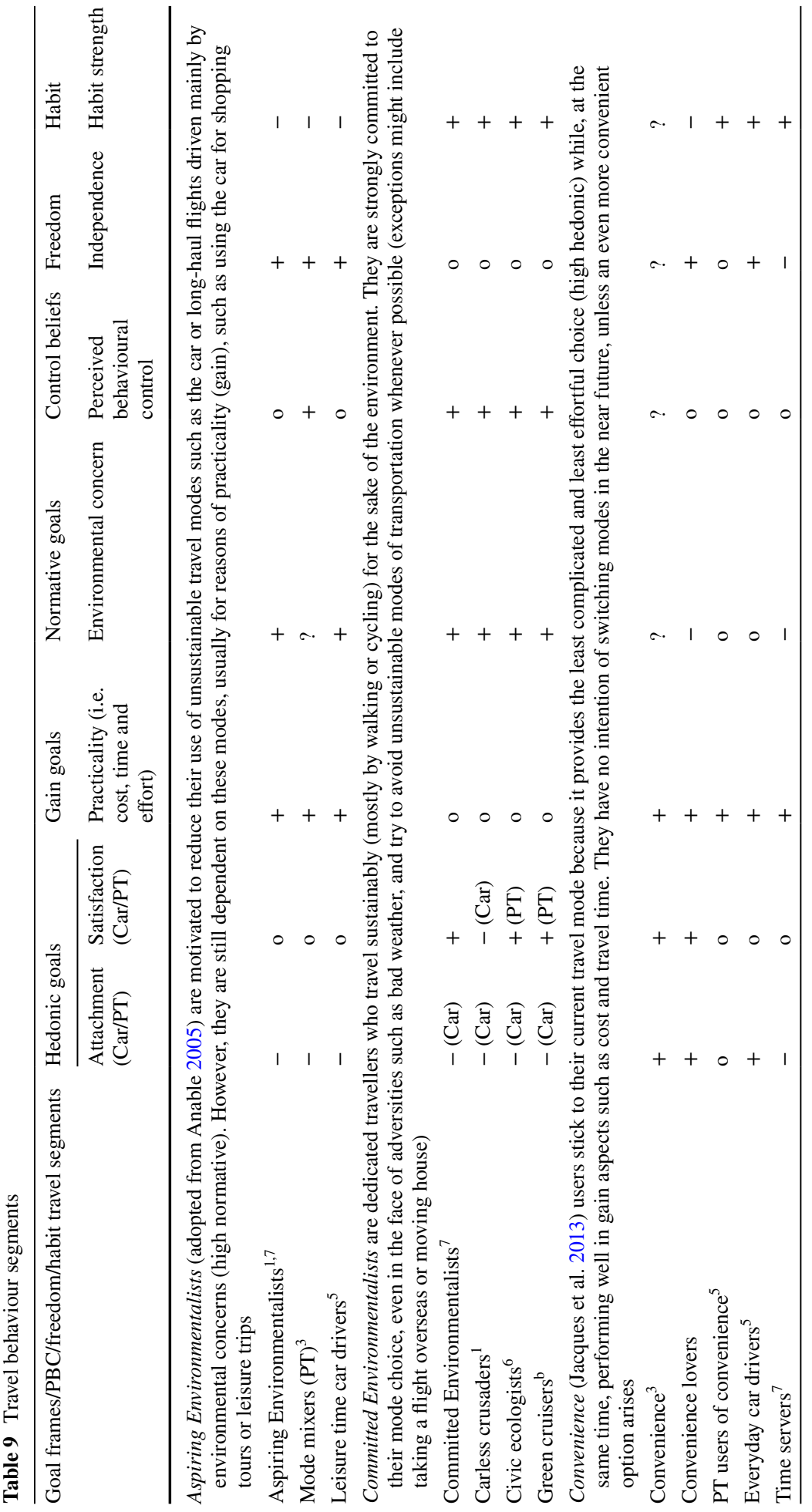




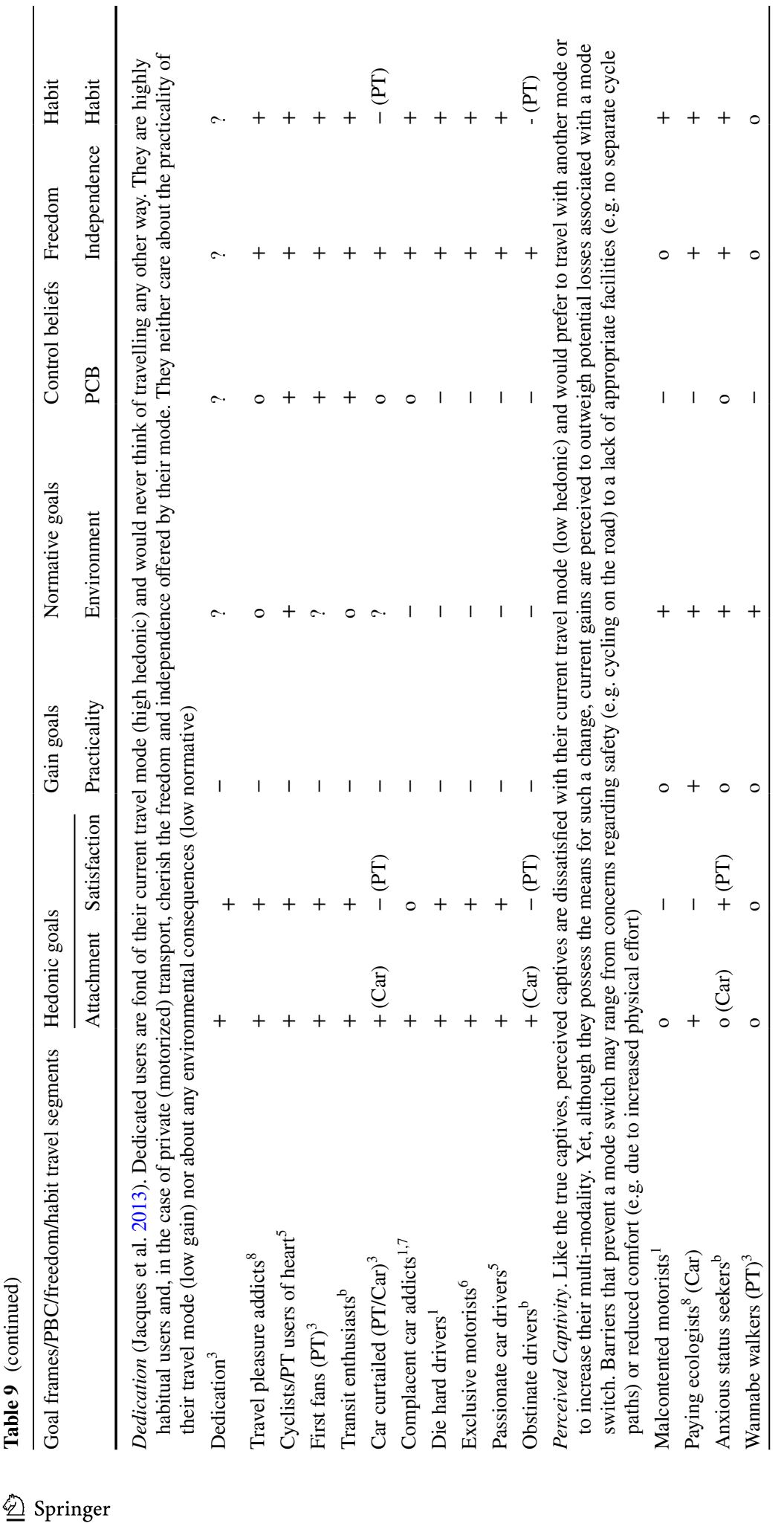




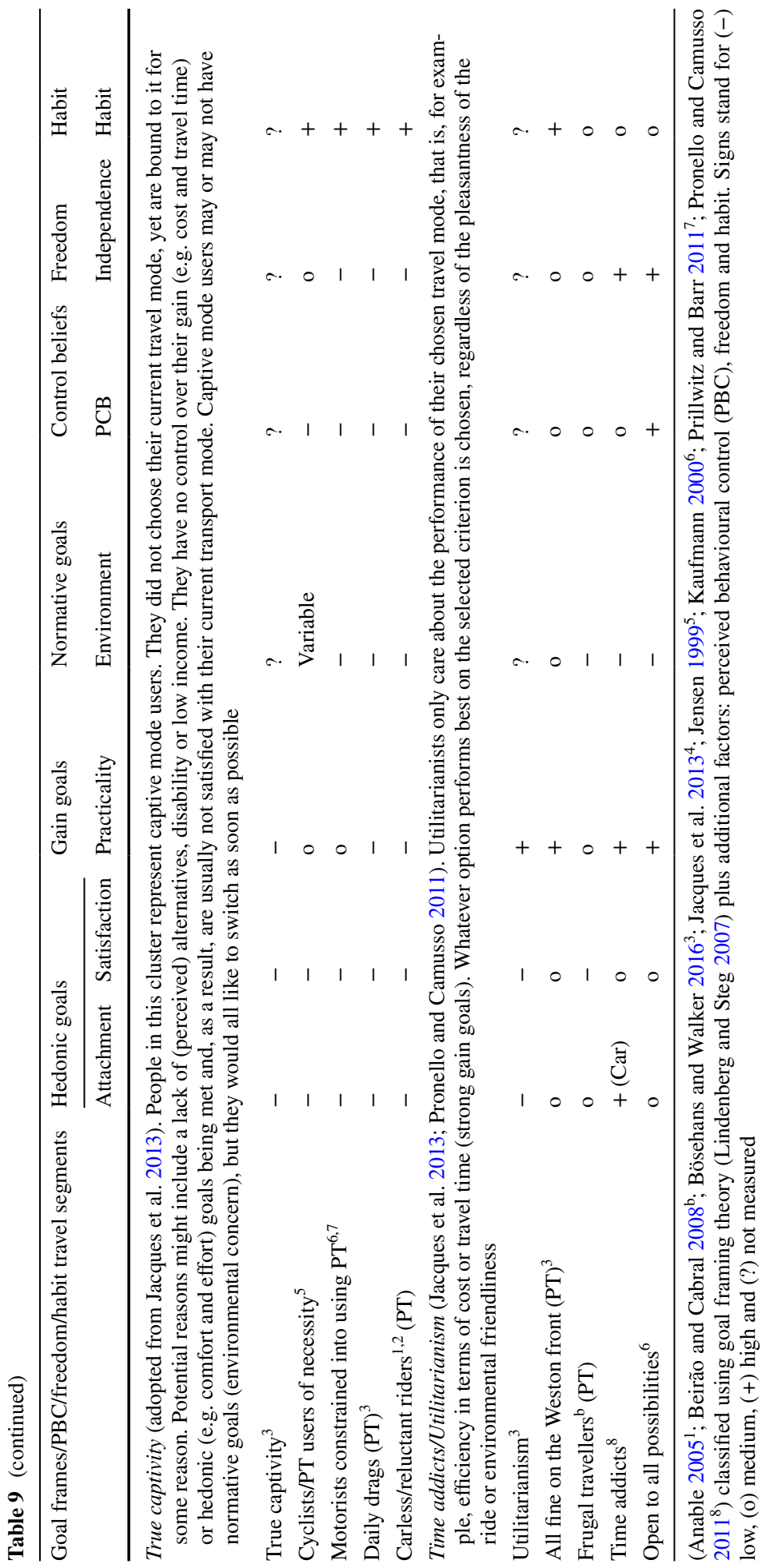




\section{References}

Ajzen, I.: The theory of planned behaviour. Organ. Behav. Hum. Decis. Process. 50, 179-221 (1991)

Ajzen, I.: The theory of planned behaviour is alive and well, and not ready to retire: a commentary on Sniehotta, Presseau, and Araújo-Soares. Health Psychol. Rev. 9(2), 131-137 (2015)

Anable, J.: 'Complacent Car Addicts' or 'Aspiring Environmentalists'? Identifying travel behaviour segments using attitude theory. Transp. Policy 12, 65-78 (2005)

Banerjee, U., Hine, J.: Identifying the underlying constructs linking urban form and travel behaviour using a grounded theory approach. Int. J. Environ. Sci. Technol. 11(8), 2217-2232 (2014)

Barr, S., Prillwitz, J.: Green travellers? Exploring the spatial context of sustainable mobility styles. Appl. Geogr. 32(2), 798-809 (2012)

Barr, S., Prillwitz, J.: A smarter choice? Exploring the behaviour change agenda for environmentally sustainable mobility. Environ. Plan. C Gov. Policy 32(1), 1-19 (2014)

Beimborn, E., Greenwald, M., Jin, X.: Accessibility, connectivity, and captivity: Impacts on transit choice. Transp. Res. Rec. J. Transp. Res. Board 1835, 1-9 (2003)

Beirão, G., Cabral, J.S.: Understanding attitudes towards public transport and private car: a qualitative study. Transp. Policy 14, 478-489 (2007)

Beirão, G., Cabral, J.S.: Market segmentation analysis using attitudes toward transportation: exploring differences between men and women. Transp. Res. Rec. J. Transp. Res. Board 2067, 56-64 (2008)

Bergstrom, A., Magnusson, R.: Potential of transferring car trips to bicycle during winter. Transp. Res. Part A 37, 649-666 (2003)

Blashfield, R.K., Aldenderfer, M.S.: The methods and problems of cluster analysis. In: Nesselroade, J.R., Cattell, R.B. (eds.) Handbook of Multivariate Experimental Psychology, pp. 447-473. Plenum Press, New York (1988)

Bockarjova, M., Steg, L.: Can protection motivation theory predict pro-environmental behavior? Explaining the adoption of electric vehicles in the Netherlands. Glob. Environ. Change 28, 276-288 (2014)

Bösehans, G., Walker, I.: 'Daily Drags' and 'Wannabe Walkers'-Identifying dissatisfied public transport users who might travel more actively and sustainably. J. Transp. Health 3(3), 395-403 (2016)

Chatterton, T.J., Coulter, A., Musselwhite, C., Lyons, G., Clegg, S.: Understanding how transport choices are affected by the environment and health: views expressed in a study on the use of carbon calculators. Public Health 123, e45-e49 (2009)

Collins, C.M., Chambers, S.M.: Psychological and situational influences on commuter-transportmode choice. Environ. Behav. 37(5), 640-661 (2005)

Cools, M., Moon, E., Janssens, B., Wets, G.: Shifting towards environment-friendly modes: profiling travelers using Q-methodology. Transportation 36, 437-453 (2009)

De Groot, J.I., Steg, L.: Value orientations to explain beliefs related to environmental significant behavior: how to measure egoistic, altruistic, and biospheric value orientations. Environ. Behav. 40(3), 330-354 (2008)

De Groot, J.I.M., Steg, L.: Morality and prosocial behavior: the role of awareness, responsibility and norms in the norm activation model. J. Soc. Psychol. 149, 425-449 (2009)

Diana, M., Mokhtarian, P.I.: Desire to change one's multimodality and its relationship to the use of different transport means. Transp. Res. Part F 12, 107-119 (2009)

Dill, J., McNeil, N.: Four types of cyclists? Transp. Res. Rec. J. Transp. Res. Board 2387(1), 129-138 (2013)

Dolnicar, S.: A review of data-driven market segmentation in tourism. J. Travel Tour. Mark. 12(1), 1-22 (2002)

Domarchi, C., Tudela, A., González, A.: Effect of attitudes, habit and affective appraisal on mode choice: an application to university workers. Transportation 35(5), 585-599 (2008)

Donald, I.J., Cooper, S.R., Conchie, S.M.: An extended theory of planned behaviour model of the psychological factors affecting commuters' transport mode use. J. Environ. Psychol. 40, 39-48 (2014)

Ewing, R., Cervero, R.: Travel and the built environment. J. Am. Plan. Assoc. 76(3), 265-294 (2010)

Faber, V.: Clustering and the continuous k-means algorithm. Los Alamos Sci. 22, 138-144 (1994)

García-Garcés, P., Ruiz, T., Habib, K.M.N.: Effect of travel behaviour change programmes on time allocated to driving. Transp. A Transp. Sci. 12(1), 1-19 (2016)

Gardner, B., Abraham, C.: What drives car use? A grounded theory analysis of commuters' reasons for driving. Transp. Res. Part F 10, 187-200 (2007)

Gärling, T., Schuitema, G.: Travel demand management targeting reduced private car use: effectiveness, public acceptability and political feasibility. J. Soc. Issues 63(1), 139-153 (2007)

Gatersleben, B., Uzzell, D.: Affective appraisals of the daily commute: comparing perceptions of drivers, cyclists, walkers, and users of public transport. Environ. Behav. 39(3), 416-431 (2007) 
Goodman, A., Sahlqvist, S., Ogilvie, D., iConnect Consortium: New walking and cycling routes and increased physical activity: one-and 2-year findings from the UK iConnect study. Am. J. Public Health 104(9), e38-e46 (2014)

Gössling, S., Cohen, S.: Why sustainable transport policies will fail: EU climate policy in the light of transport taboos. J. Transp. Geogr. 39, 197-207 (2014)

Gower, J.C.: A comparison of some methods of cluster analysis. Biometrics 23(4), 623-637 (1967)

Graham-Rowe, E., Skippon, S., Gardner, B., Abraham, C.: Can we reduce car use and if so, how? A review of available evidence. Transp. Res. Part A Policy Pract. 45(5), 401-418 (2011)

Heath, G.W., Brownson, R.C., Kruger, J., Miles, R., Powell, K.E., Ramsey, L.T., Task Force on Community Preventive Services: The effectiveness of urban design and land use and transport policies and practices to increase physical activity: a systematic review. J. Phys. Act. Health 3(s1), S55-S76 (2006)

Hensher, D.A.: Climate change, enhanced greenhouse gas emissions and passenger transport-what can we do to make a difference? Transp. Res. Part D Transp. Environ. 13(2), 95-111 (2008)

Innocenti, A., Lattarulo, P., Pazienza, M.G.: Car stickiness: heuristics and biases in travel choice. Transp. Policy 25, 158-168 (2013)

Jacques, C., Manaugh, K., El-Geneidy, A.M.: Rescuing the captive [mode] user: an alternative approach to transport market segmentation. Transportation 40, 625-645 (2013)

Jain, S., Aggarwal, P., Kumar, P., Singhal, S., Sharma, P.: Identifying public preferences using multi-criteria decision making for assessing the shift of urban commuters from private to public transport: a case study of Delhi. Transp. Res. Part F Traffic Psychol. Behav. 24, 60-70 (2014)

Jaśkiewicz, M., Besta, T.: Heart and mind in public transport: analysis of motives, satisfaction, and psychological correlates of public transportation usage in the Gdańsk-Sopot-Gdynia Tricity Agglomeration in Poland. Transp. Res. Part F 26, 92-101 (2014)

Jensen, M.: Passion and heart in transport-a sociological analysis on transport behaviour. Transp. Policy 6 , 19-33 (1999)

Khan, M., Kockelman, K.M., Xiong, X.: Models for anticipating non-motorized travel choices, and the role of the built environment. Transp. Policy 35, 117-126 (2014)

Kaufmann, V.: Modal practices: from the rationales behind car and public transport use to coherent transport policies. Case studies in France and Switzerland Vincent Kaufmann. Editor. Board 6(3), 8-17 (2000)

Klöckner, C.A., Matthies, E.: How habits interfere with norm-directed behaviour: a normative decisionmaking model for travel mode choice. J. Environ. Psychol. 24(3), 319-327 (2004)

Krizek, K.J., El-Geneidy, A.: Segmenting preferences and habits of transit users and non-users. J. Public Transp. 10(3), 71-94 (2007)

Krueger, R., Vij, A., Rashidi, T.H.: Normative beliefs and modality styles: a latent class and latent variable model of travel behaviour. Transportation (2016). https://doi.org/10.1007/s11116-016-9751-1

LaJeunesse, S., Rodríguez, D.A.: Mindfulness, time affluence, and journey-based affect: exploring relationships. Transp. Res. Part F Traffic Psychol. Behav. 15(2), 196-205 (2012)

Larsen, J., El-Geneidy, A.: A travel behavior analysis of urban cycling facilities in Montréal, Canada. Transp. Res. Part D Transp. Environ. 16(2), 172-177 (2011)

Lindenberg, S., Steg, L.: Normative, gain, and hedonic goal frames guiding environmental behaviour. J. Soc. Issues 65(1), 117-137 (2007)

Lindenberg, S., Steg, L.: Goal-framing theory and norm-guided environmental behavior. In: van Trijp, H.C.M. (ed.) Encouraging sustainable behaviour, pp. 37-54. Psychology Press, New York (2013)

Lois, D., López-Sáez, M.: The relationship between instrumental, symbolic and affective factors as predictors of car use: a structural equation modeling approach. Transp. Res. Part A Policy Pract. 43(9-10), 790-799 (2009)

López-Sáez, M., Lois, D., Morales, J.F.: Influence on the choice of transportation mode of travel time variability, personal benefits, and environmental damage from cars versus public transportation. Ann. Psychol. 32(2), 555-564 (2016)

Mann, E., Abraham, C.: The role of affect in UK commuters' travel mode choices: An interpretative phenomenological analysis. Br. J. Psychol. 97, 155-176 (2006)

Milligan, G.W.: An examination of the effect of six types of error perturbation on fifteen clustering algorithms. Psychometrika 45(3), 325-342 (1980)

Möser, G., Bamberg, S.: The effectiveness of soft transport policy measures: a critical assessment and metaanalysis of empirical evidence. J. Environ. Psychol. 28(1), 10-26 (2008)

Murtagh, N., Gatersleben, B., Uzzell, D.: Self-identity threat and resistance to change: evidence from regular travel behaviour. J. Environ. Psychol. 32(4), 318-326 (2012)

Næss, P.: Built environment, causality and travel. Transp. Rev. 35(3), 275-291 (2015)

Olsson, L.E., Gärling, T., Ettema, D., Friman, M., Fujii, S.: Happiness and satisfaction with work commute. Soc. Indic. Res. 111(1), 255-263 (2013) 
Paulssen, M., Temme, D., Vij, A., Walker, J.L.: Values, attitudes and travel behavior: a hierarchical latent variable mixed logit model of travel mode choice. Transportation 41, 873-888 (2014)

Peattie, K., Peattie, S.: Social marketing: a pathway to consumption reduction? J. Bus. Res. 62(2), 260-268 (2009)

Pooley, C.G., Horton, D., Scheldeman, G., Mullen, C., Jones, T., Tight, M., et al.: Policies for promoting walking and cycling in England: a view from the street. Transp. Policy 27, 66-72 (2013)

Prillwitz, J., Barr, S.: Moving towards sustainability? Mobility styles, attitudes and individual travel behaviour. J. Transp. Geogr. 19(6), 1590-1600 (2011)

Pronello, C., Camusso, C.: Travellers' profiles definition using multivariate statistical analysis of attitudinal variables. J. Transp. Geogr. 19, 1294-1308 (2011)

Pronello, C., Rappazzo, V.: The modal diversion induced by high quality public transport: use of attitudinal variables for travellers' segmentation. In: Proceedings of the 12th WCTR, Lisbon, Portugal (2010)

Punj, G., Stewart, D.W.: Cluster analysis in marketing research: review and suggestions for application. J. Mark. Res. 20(2), 134-148 (1983)

Redman, L., Friman, M., Gärling, T., Hartig, T.: Quality attributes of public transport that attract car users: a research review. Transp. Policy 25, 119-127 (2013)

Rokeach, M.: The Nature of Human Values. Free Press, New York (1973)

Rubens, L., Gosling, P., Moch, A.: Investigating justifications concerning transport mode choice in order to promote public transport. Prat. Psychol. 17, 19-29 (2011)

Schneider, R.J.: Theory of routine mode choice decisions: an operational framework to increase sustainable transportation. Transp. Policy 25, 128-137 (2013)

Schuitema, G., Anable, J., Skippon, S., Kinnear, N.: The role of instrumental, hedonic and symbolic attributes in the intention to adopt electric vehicles. Transp. Res. Part A Policy Pract. 48, 39-49 (2013)

SEGMENT: Segmented marketing for energy efficient transport. Retrieved Sept 24, 2016, from http://www. segmentproject.eu/hounslow/segment.nsf/ (2016)

Sniehotta, F.F., Presseau, J., Araújo-Soares, V.: Time to retire the theory of planned behaviour. Health Psychol. Rev. 8(1), 1-7 (2014)

Sokal, R.R., Michener, C.D.: A statistical method for evaluating systematic relationships. Univ. Kansas Sci. Bull. 38, 1409-1438 (1958)

Steg, L.: Car use: lust and must. Instrumental, symbolic and affective motives for car use. Transp. Res. Part A 39, 147-162 (2005)

Steg, L., Vlek, C.: Encouraging pro-environmental behaviour: an integrative review and research agenda. J. Environ. Psychol. 29(3), 309-317 (2009)

Steg, L., Bolderdijk, J.W., Keizer, K., Perlaviciute, G.: An integrated framework for encouraging pro-environmental behaviour: the role of values, situational factors and goals. J. Environ. Psychol. 38, 104-115 (2014a)

Steg, L., Lindenberg, S., Keizer, K.: Intrinsic motivation, norms and environmental behaviour: the dynamics of overarching goals. Int. Rev. Environ. Resour. Econ. 9(1-2), 179-207 (2016)

Steg, L., Perlaviciute, G., Van der Werff, E., Lurvink, J.: The significance of hedonic values for environmentally relevant attitudes, preferences, and actions. Environ. Behav. 46(2), 163-192 (2014b)

Steg, L., Vlek, C., Slotegraaf, G.: Instrumental-reasoned and symbolic-affective motives for using a motor car. Transp. Res. Part F Traffic Psychol. Behav. 4(3), 151-169 (2001)

St-Louis, E., Manaugh, K., van Lierop, D., El-Geneidy, A.: The happy commuter: a comparison of commuter satisfaction across modes. Transp. Res. Part F Traffic Psychol. Behav. 26, 160-170 (2014)

Stradling, S.G.: Transport user needs and marketing public transport. Proc. Inst. Civ. Eng. Munic. Eng. 151(1), 23-28 (2002)

Tertoolen, G., van Kreveld, D., Verstraten, B.: Psychological resistance against attempts to reduce private car use. Transp. Res. Part A 32(3), 171-181 (1998)

Thomas, G.O.: Exploring alternatives to rational choice in models of behaviour: an investigation using travel mode choice. Doctoral dissertation, University of Bath. Retrieved September 12, 2017, from http:// ethos.bl.uk/OrderDetails.do?uin=uk.bl.ethos.619230 (2014)

Thomas, G.O., Walker, I.: Users of different travel modes differ in journey satisfaction and habit strength but not environmental worldviews: a large-scale survey of drivers, walkers, bicyclists and bus users commuting to a UK university. Transp. Res. Part F Traffic Psychol. Behav. 34, 86-93 (2015)

Thomas, G.O., Walker, I., Musselwhite, C.: Grounded theory analysis of commuters discussing a workplace carbon-reduction target: autonomy, satisfaction, and willingness to change behavior in drivers, pedestrians, bicyclists, motorcyclists, and bus users. Transp. Res. Part F 26, 72-81 (2014)

Tørnblad, S.H., Westskog, H., Rose, L.E.: Does location matter? Public acceptance of restrictive policy measures at the local level. J. Environ. Policy. Plan. 16(1), 37-54 (2014) 
Verplanken, B., Aarts, H., Knippenberg, A.: Habit, information acquisition, and the process of making travel mode choices. Eur. J. Soc. Psychol. 27, 539-560 (1997)

Verplanken, B., Orbell, S.: Reflections on past behavior: a self-report index of habit strength. J. Appl. Soc. Psychol. 33(6), 1313-1330 (2003)

Verplanken, B., Roy, D.: Empowering interventions to promote sustainable lifestyles: testing the habit discontinuity hypothesis in a field experiment. J. Environ. Psychol. 45, 127-134 (2016)

Walker, I., Thomas, G.O., Verplanken, B.: Old habits die hard: travel habit formation and decay during an office relocation. Environ. Behav. (2014). https://doi.org/10.1177/0013916514549619

Ward, J.: Hierarchical grouping to optimize an objective function. J. Am. Stat. Assoc. 58, 236-244 (1963)

Zhibin, L., Wang, W., Yang, C., Ragland, D.R.: Bicycle commuting market analysis using an attitudinal market segmentation approach. Transp. Res. Part A 47, 56-68 (2013)

Gustav Bösehans is a recent PhD graduate at the University of Bath. His research interests include behaviour change (or soft) and urban design (or hard) measures in the context of travel mode choice and other proenvironmental behaviours. Gustav is currently working as a postgraduate researcher on the ZooWise project (zoowise.org) and other research activities for the independent research enterprise Qualia Analytics Ltd.

Ian Walker is a Transport and Environmental Psychologist and Associate Dean for Research at the University of Bath, UK. His current research interests include the human side of traffic, transportation, energy and water use behaviours, covering such topics as transport mode choice, bicyclist safety, the effects of motorcycle noise on hearing and concentration, home energy consumption, smart meters and electric vehicles. In addition, Ian currently leads the Water Awareness and Behaviour stream within the University of Bath's Water Innovation and Research Centre (WIRC). 